University of Massachusetts Amherst

ScholarWorks@UMass Amherst

Masters Theses 1911 - February 2014

1984

Crystalline-state extrusion of low density polyethylenes/

Chadli Benelhadjsaid

University of Massachusetts Amherst

Follow this and additional works at: https://scholarworks.umass.edu/theses

Benelhadjsaid, Chadli, "Crystalline-state extrusion of low density polyethylenes/" (1984). Masters Theses 1911 - February 2014. 1313.

https://doi.org/10.7275/0ye1-m560

This thesis is brought to you for free and open access by ScholarWorks@UMass Amherst. It has been accepted for inclusion in Masters Theses 1911 - February 2014 by an authorized administrator of ScholarWorks@UMass Amherst. For more information, please contact scholarworks@library.umass.edu. 


\title{
CRYSTALLINE-STATE EXTRUSION \\ OF LOW DENSITY POLYETHYLENES
}

\section{A Thes is Presented}

By

Chadli Benelhadjsaid

\begin{abstract}
Submitted to the Graduate School of the University of Massachusetts in partial fulfillment of the requirements for the degree of
\end{abstract} MASTER OF SCIENCE February 1984

Polymer Science and Engineering Department 
CRYSTALLINE-STATE EXTRUSION

OF LOW DENSITY POLYETHYLENE

A Thesis Presented

By

Chad li Benelhadjsaid

Approved as to Style and Content by

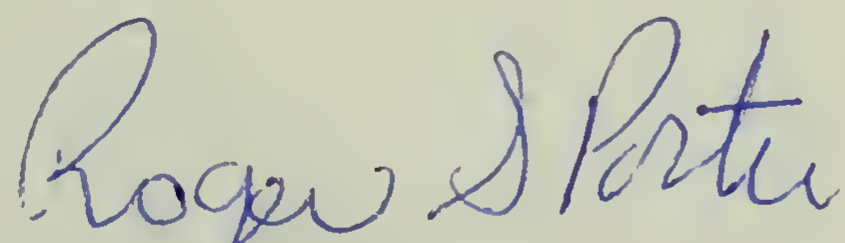

Professor Roger S. Porter

Chairperson of Committee

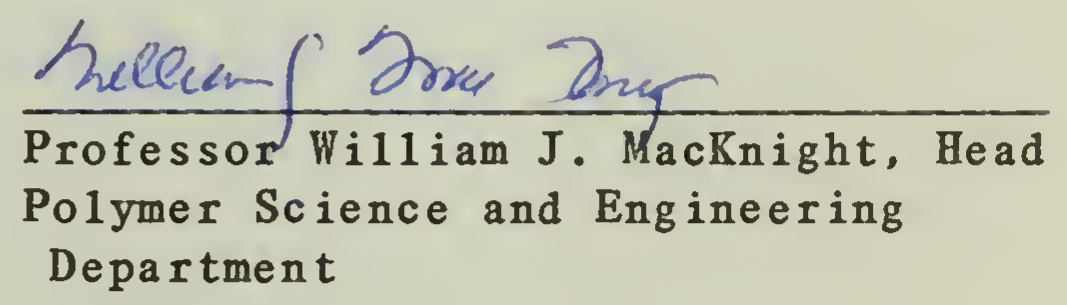

ii 
Dedication:

To: Dad

Mom

Amina

D j ame 1

Mounira

My Uncle Dahmane

My Aunt Naziha

My Uncle Larbi

A11 my relatives

The Mahoods 


\section{ACKNOWLEDGEMENTS}

I extend my deepest thanks and appreciation to Dr. Roger S. Porter for his guidance, support, encouragement and understanding. I wish to thank Dr. Richard J. Farris for his help and advice. Thanks is also due to Dr. A. Nicco of CdF Chimie (France) for providing the LLDPE samples. Sincere appreciation is accorded to Dr. T. Kanamoto of Science University of Tokyo for providing $\mathrm{x}$-ray data, and my colleagues Mr. J. Jonza and Mr. J. Parmer for their thermal conductivity data. I am also grateful to the members of the research group for their help, cooperation and friendship. I am indebted to Sonatrach Company (Algeria) for their financial support. Finally, a special thanks is reserved to all my friends (particularly Phyllis Woolf) for their help and for making my stay in the USA such a pleasant one. 


\title{
ABSTRACT \\ CRYSTALLINE-STATE EXTRUSION \\ OF LOW DENSITY POLYETHYLENES
}

February 1984

\begin{abstract}
Chadli Benelhadjsaid, B.S., I.A.P. Boumerdes, Algeria M.S., University of Massachusetts

Directed by: Professor Roger S. Porter
\end{abstract}

Three low density polyethylenes, one long branched (A) and two linear ( $B$ and $C$ ), have been solid-state extruded at different temperatures from ambient to $80^{\circ} \mathrm{C}$ and to draw ratios $\leq 8$. The densities and me $1 \mathrm{t}$ indices of $\mathrm{A}, \mathrm{B}$ and $\mathrm{C}$ are $0.920,0.920$ and $0.935 \mathrm{~g} / \mathrm{cm}^{3}$, and 1.9, 0.8 and 1.2 respectively. Me1t crystallized billets were extruded through conical dies in an Instron Capillary Rheometer. The linear polymers draw more easily than the branched. All three strain-harden. Density, birefringence, tensile and thermal properties have been evaluated as functions of extrusion temperature and draw ratio. Despite some loss through die swell, substantial orientation takes place during solid-state extrusion as evidenced by increases in transparency, birefringence, tensile modulus (up to 4.5 times that of the original isotropic polymer) and thermal conductivity. No major changes in crystallinity were observed as assessed by density and DSC measurements. Depending on the polymer and the draw temperature, density does go through a minimum or shows a monotonic increase with draw. A minimum in modulus is also observed at low draw and at all draw temperatures for 
all three polymers. The highest tensile moduli achieved are $0.73,0.46$ and $1.5 \mathrm{GPa}$ for $\mathrm{A}, \mathrm{B}$ and $\mathrm{C}$ respectively at their highest draw ratios. The melting point for polymer B decreases with draw ratio whereas it remains constant after a small drop at low draw for the two others. For a11, birefringence increases rapidly with draw and then levels off at high draw. The birefringence 1 imit is similar for $A$ and $B, i . e .0 .046 \pm$ 0.004 , but higher for $C$, i.e. $0.068 \pm 0.009$. First measurements of thermal conductivity show a 1 inear increase with draw along the orientation direction. 
DEDICATION $\ldots \ldots \ldots$

ACKNOWLEDGEMENT

ABSTRACT

CHAPTER

I. Introduction $-\ldots \ldots-\ldots$

II. Experimental $---_{-}-\ldots-\ldots-\ldots$

1. Polymer materials $-\ldots \ldots$

2. Billet preparation - - - - - - - - - - 4

3. Drawing process - - - - - - - - - - - 4

4. Density measurements - $-\ldots$

5. Thermal analysis $-\ldots-\ldots-\ldots$

6. Mechanical tests $-\ldots-\ldots-\ldots$

7. Birefringence $-\ldots \ldots$ 7

III. Extrusion Characteristics - - - - - - - - - 8

1. Extrusion analysis - - - - - - - - - - 8

2. Extrudate quality - - - - - - - - - - 19

3. Extrudate expansion _ - - - $-\ldots 29$

4. Extrusion draw ratios - - - $-\ldots+\ldots 35$

5. Coefficient of friction $-\ldots+\ldots 40$

IV. Properties $---_{-}--_{-}--_{-}-{ }_{-}-{ }^{-} 43$

1. Fractional crystallinity $-\ldots+\ldots 43$

1.1 From density - $-\ldots \ldots 43$

1.2 From heat of fusion $-\ldots+\ldots 51$

2. Me1ting temperatures - $-\ldots-\ldots 56$

2.1 Melting point $-\ldots+\ldots 56$

2.2 Multiple melting peaks - $-\ldots$

3. Tensile modulus - $-\ldots \ldots$ - $-\ldots 4$

4. Orientation - $-\ldots \ldots 71$

4.1 Birefringence $-\ldots-\ldots 71$

4.2 Thermal conductivity $-\ldots+\ldots 80$

V. Conclusion $-\ldots \ldots-\ldots$

Selected Bibliography $-\ldots-\ldots-\ldots-\ldots$

Appendix: Relaxation modulus $-\ldots$ 


\section{List of Tables}

Table

1 Characteristics of Polyethylene Samples Studied - - - - 3

2 Billet Preparation Conditions - $\ldots$

3 Plunger Velocity for Sample A Extrusion - - - - $\ldots$

4 Plunger Velocity for Sample B Extrasion - _ _ $\ldots$

5 Plunger Velocity for Sample C Extrusion - _ - - - _ - 13

6 Sample A Extrudate Quality _ _ _ $\ldots$ - $\ldots$ - $\ldots$

7 Sample B Extrudate Quality $\ldots \ldots \ldots$

8 Sample C Extrudate Quality _ _ _ $\ldots+\ldots$

9 Minimum Die Swe11 Temperature $\left({ }^{\circ} \mathrm{C}\right) \ldots \ldots$

10 EDR for Sample A $\ldots+\ldots-\ldots$

11 EDR for Sample B $\ldots \ldots \ldots$ - 37

12 EDR for Sample $C$ - $-\ldots-\ldots-\ldots$

13 (EDR* - EDR) for Sample A $\ldots+\ldots-\ldots$

14 (EDR* - EDR) for Sample B $-\ldots \ldots$

15 (EDR* - EDR) for Sample C - - - - - - - $-\ldots$ - 39

16 Coefficient of Friction - Sample A - - - - - - - 41

17 Coefficient of Friction - Sample B - - - - - - - 42

18 Coefficient of Friction - Sample C - - - - - - 42

19 Crysta11inity (\%) from Density for Sample A - - - - 44

20 Crystallinity (\%) from Density for Sample B - - - - - 44

21 Crystallinity (\%) from Density for Sample C - - - - - 45

22 Overal1 Density Change $-\ldots-\ldots$

23 Crystalinity (\%) from Heat of Fusion for Sample A - - 52 
24 Crystallinity (\%) from Heat of Fusion for Sample B - - 53

25 Crystallinity (\%) from Heat of Fusion for Sample C - - 54

26 Difference Between Crystallinities from Density and Heat of Fusion $-\ldots \ldots 55$

27 Presently Achievable Tensile Moduli of Polyethylene - - 69

28 Stress Output to Strain Input Ratio - $\ldots$

29 Relaxation Modulus of Polymer A Extruded at $80^{\circ} \mathrm{C}$ and $D R=3.0$ for Different Strain Rates and Relaxation

Times $\ldots \ldots \ldots$ 


\section{ILLUSTRATIONS}

Figure

1 Extruder $\quad \ldots-\ldots-\ldots$

2 Recorded Pressure as a Function of Extrusion Time for Sample C. $\mathrm{T}_{\text {ex }}=40^{\circ} \mathrm{C}$ and Plunger Velocity $0.1 \mathrm{~cm} / \mathrm{min}$

3 Sample A Extrusion Pressure versus Strain at Various

Extrusion Temperatures $\ldots \ldots$

4 Sample B Extrusion Pressure versus Strain at Various

Extrusion Temperatures ${ }_{-}-\ldots$

5 Sample C Extrusion Pressure versus Strain at Various

Extrusion Temperatures $-\ldots \ldots$

6 Extrudate Die Swe11 for Sample A versus Extrusion

Temperature for Various Draw Ratios - $\ldots$

7 Extrudate Die Swe11 for Sample B versus Extrusion

Temperature for Various Draw Ratios - - . - - . -

8 Extrudate Die Swe11 for Sample C versus Extrusion

Temperature for Various Draw Ratios - $\ldots$

9 Density of Sample A Extrudates versus EDR at Various

Extrusion Temperatures $-\ldots+\ldots 46$

10 Density of Sample B Extrudates versus EDR at Various

Extrusion Temperatures - $\ldots \ldots \ldots$

11 Density of Sample C Extrudates versus EDR at Various

Extrusion Temperatures ${ }_{-}-\ldots$

12 Peak Me1ting Point Versus EDR for Samples A, B and C

Extruded at $80^{\circ} \mathrm{C} \ldots \ldots$

13 DSC Endotherms for Sample A Extruded at $80^{\circ} \mathrm{C}$ at

Various EDR - $-\ldots \ldots \ldots$

14 DSC Endotherms for Sample B Extruded at $80^{\circ} \mathrm{C}$ at

Various EDR - $\ldots \ldots \ldots$

15 DSC Endotherms for Sample C Extruded at $80^{\circ} \mathrm{C}$ at

Various EDR - - - - - - - - - - - - - - -

16 Tensile Modulus Versus EDR for Sample A at Various

Extrusion Temperatures $-\ldots+\ldots$ 
17 Tensile Modulus Versus EDR for Sample B at Various

Extrusion Temperatures ${ }_{-} \ldots \ldots+\ldots 66$

18 Tensile Modulus Versus EDR for Sample C at Various

Extrusion Temperatures _ $-\ldots+\ldots 67$

19 Total Birefringence Versus EDR for A, B, and C Extruded at Room Temperature - $\ldots \ldots \ldots$

20 Total Birefringence Versus EDR for Sample A Extruded at 22 and $80^{\circ} \mathrm{C}-\ldots \ldots$

21 Crysta11ine and Amorphous Orientation Functions Versus EDR for Sample A Extruded at Room Temperature - - - -

22 Crystalline and Amorphous Contributions to Birefringence of Sample A Extruded at Room Temperature - - - - -

23 Axial Thermal Conductivity Versus EDR for Samples A and $\mathrm{B}$ Extruded at $60^{\circ} \mathrm{C} \ldots \ldots$

24 Strain Input and Relaxation Modulus in a Ramp Loaded

Stress Relaration $-\ldots \ldots$

P1 a te

1 Sample A Extrudate $-\mathrm{T}_{\mathrm{ex}}=80^{\circ} \mathrm{C} \ldots \ldots-\ldots$

2 Sample B Extrudate $-\mathrm{T}_{\mathrm{ex}}=80^{\circ} \mathrm{C}-\ldots-\ldots$

3 Sample C Extrudate $-\mathrm{T}_{\text {ex }}=80^{\circ} \mathrm{C}-\ldots-\ldots$ 


\section{H A P T E R I}

\section{INTRODUCTION}

Crystalline (solid) state extrusion of several thermoplastics has been studied extensively over this past decade to produce oriented morphologies. Despite the fact that low density polyethylene (LDPE) is the largest volume thermoplastic in the world, 1 it has been involved in only a few such studies: note the solid-state and hydrostatic extrusions by Buckley and Long ${ }^{2}$ and Alexander and Worme $11^{3}$ respectively. The advent of 1 inear LDPE resins has opened new opportunities for studying the effect of short as well as long branches in solid-state extrusion. Thus, the purpose of this study is not only to evaluate the property changes achieved through uniaxial orientation of three low density polyethylenes but also to compare the linear and long branched LDPE polymers and also LDPE vs. HDPE. LDPE solid-state extrusion has not been previously studied in our laboratory, only HDPE. ${ }^{4-15}$ Consideration will also be given to the differences and similarities between solid-state extrusion and cold drawing in inducing high uniaxial orientation. Four principal methods of characterization are used: thermal analysis and density, tensile and birefringence measurements. Thermal conductivity measurements are also being undertaken in collaboration with others at the University of Massachusetts. The variables of draw are extrusion temperature and draw ratio. Additional properties such as die swell and transparency are considered. 


\section{EXPERIMENTAL}

\section{Polymer Materials}

Three polyethylenes were used in this study: one long branched low density (LDPE) and two linear low density polyethylenes (LLDPE). Their properties, as provided by the producers, are 1 isted in Table 1 . In the text, these polyethylenes will be referred to as $A, B$ and $C$. $A$ is the polymer with long branches whereas $B$ and $C$ are linear. The choice of these three polymers enables us to investigate. The influence on the extrusion process and the properties of:

(i) long chain branching, on comparing $A$ and $B$ which have the same crysta 11 inity,

(ii) short chain branching content by comparing $B$ and $C$ which have different crystallinity.

We will also extend the comparison to high density polyethylene for which abundant information is available in the literature. 
Table 1

Characteristics of Polyethylene Samples Studied

\begin{tabular}{|c|c|c|c|c|c|c|c|}
\hline Sample & Type & Grade & Manufacturer & $\stackrel{\rho,}{g / \mathrm{cm}^{3}}$ & MI* & $\bar{M}_{n} * *$ & $\begin{array}{c}\text { Crystal1inity } \\
\qquad(\%) * * *\end{array}$ \\
\hline A & LDPE & A1 a thon 20 & duPont & 0.920 & 1.9 & 32,000 & 49 \\
\hline B & LLDPE & FW 1290 & CdF Chimie & 0.920 & 0.8 & 36,000 & 49 \\
\hline C & LLDPE & FW 1180 & CdF Chimie & 0.935 & 1.2 & 34,000 & 59 \\
\hline
\end{tabular}

*ASTM D 1238, me1t index

**Calculated from Equation 1

***Ca1culated from density

To estimate the molecular weight of our polymers, a relation (Equation 1 ) between the number average molecular weight $\left(\bar{M}_{n}\right)$ and the me1t flow index (MI) has been used. This correlation has been applied to 1 ow density polyethylenes. ${ }^{16}$ As the density increases, number averages calculated from Equation 1 will err on the high side. ${ }^{16}$ This means that $\bar{M}_{n}$ of polymer $C$ is likely slightly lower than 34,000 .

$$
\left(M_{n}\right)^{1 / 2}=188-30 \log (M I)
$$




\section{Billet Preparation}

The billets to be extruded were prepared in the barrel of an Instron capillary rheometer. The original polymer was melted under a pressure $P_{c}$ at a temperature $T_{1}$ above its me1ting point (See Table 2). To avoid the formation of voids, it was then recrystallized by cooling while still under the same pressure Pc. The cooling rate did not exceed $1{ }^{\circ} \mathrm{C} / \mathrm{min}$. The pressure was then released at a temperature $\mathrm{T}_{2}$ below its ambient pressure melting point. The preparation conditions are summarized in Table 2 .

Table 2

Billet Preparation Conditions

\begin{tabular}{cccc}
\hline Polyethylene & $\mathrm{P}_{\mathrm{c}}(\mathrm{MPa})$ & $\mathrm{T}_{1}\left({ }^{\circ} \mathrm{C}\right)$ & $\mathrm{T}_{2}\left({ }^{\circ} \mathrm{C}\right)$ \\
\hline A & 150 & 172 & 80 \\
$\mathrm{~B}$ & 64 & 162 & 85 \\
$\mathrm{C}$ & 64 & 162 & 85 \\
\hline
\end{tabular}

\section{Drawing Process}

The extrusion was carried out in the Instron Rheometer at four different constant temperatures, a11 below the ambient melting point: 
room temperature, 40,60 and $80^{\circ} \mathrm{C}$ for each of the three polymers. The billet was pushed through a brass conical die of entrance angle $20^{\circ}$ at constant speed. The length-to-diameter ratio (L/D) of the die capillary is kept constant at 2.0. The pressure, which varies with time, is chart recorded. The extrusion rate, which is used along with the Instron speed to determine the extrusion draw ratio, is determined by following the motion of the extrudate using a cathetometer. In order to keep the extruded strand straight, a sma11 weight of $260 \mathrm{~g}$ is attached to it. The tensile force developed is negligible compared to the extrusion pressure. A micrometer was used to measure the extrudate diameter.

\section{Density Measurements}

The density of the extrudates was measured in a density gradient column using a mixture of water and isopropanol with calibrated glass floats at $(23.0 \pm 0.1)^{\circ} \mathrm{C}$. A water-bath was used to control the temperature. The value reported for each sample is the average of three measurements with an uncertainty that does not exceed $\pm 0.0003 \mathrm{~g} / \mathrm{cm}^{3}$.

\section{Therma1 Analys is}

The melting point and the heat of fusion were measured using a Perkin-E1mer DSC-2. The calculations were made by a computer using a TADS program. Two standards - naphthalene and indium - were used for temperature calibration. All measurements for the three polymers were made at a heating rate of $10^{\circ} \mathrm{C} / \mathrm{min}$. The melting point (MP) was defined 
as the peak value of the fusion curve. The MP reported for each sample is the average of at least three measurements.

\section{Mechanical Tests}

The tensile properties of polymers $A, B$ and $C$, were measured by a relaxation modulus in tension instead of the conventional Young's modulus for the following reasons:

(i) The initial region of the stress strain curve of our samples is not elastic even at $\varepsilon \leq 0.1 \%$.

(ii) Most of the extrudates are curved, adding uncertainty.

(iii) Our samples are linearly viscoelastic within an uncertainty of less than $15 \%$ for strains $\varepsilon \leq 1 \%$ (see Appendix).

The relaxation moduli were measured by carrying out a ramp-loaded stress relaxation test on an Instron at room temperature using strain gage extensometer of $25 \mathrm{~mm}$ gage length. The sample is stretched at a speed of $0.05 \mathrm{~cm} / \mathrm{min}$ for $1 \mathrm{~min}$. The machine is then stopped and the sample is allowed to relax while the strain is kept constant. The stress relaxation modulus is calculated by dividing the stress reported after 4 min of relaxation by the constant strain (see Appendix). The initial gage length of all samples is $5 \mathrm{~cm}$ and the strain rate is $\sim 10^{-4}$ $\sec ^{-1}$. An initial load of $9 \mathrm{~N}$ is applied for all samples prior to any stretching in order to account for any initial sample curvature. This initial load does not affect the precision of the results which is of 17\%. The grips used are modified tap wrenches. 


\section{Birefringence}

Birefringence was measured using a Zeiss Calspar tilting compensator with a Zeiss polarizing microscope and a white light source $(5500 \AA$ wavelength). The total birefringence $\Delta n_{T}$ of the extrudates was evaluated from the following equation: 17

$$
\Delta \mathrm{n}_{\mathrm{T}}=\frac{\mathrm{R}}{\mathrm{d}} \cdot \lambda
$$

where $d$ is the sample thickness, $R$ the retardation and $\lambda$ the wavelength. Thin samples for testing were cut from the extrudates using either a razor blade (for polymer A) or a rotary microtome with glass knives (for polymers $B$ and $C$ ). The second method induces some orientation effects. 17 Consequently, the uncertainty in the birefringence is as high as $20 \%$ at low draw ratios for samples $B$ and $C$. 


\section{C \\ EXTRUSION CHARACTERISTICS}

\section{Extrusion Analysis}

The material on extrusion travels through three distinct regions (Figure 1). It traverses the barrel (region I) of constant diameter before it enters the cone of the die (region II). In this region, because of the decrease in cross-section area, the polymer undergoes a deformation that is mainly elongationa $1.4,18$ Once in the capillary, it is not drawn any further. The ratio between the entrance (point B) and the exit (point D) cross-sectional areas of the die expresses the extent of deformation or drawing and is referred to as the draw ratio (DR). The final product or extrudate is characterized by three parameters: $D R$, the temperature of extrusion, $T$ ex, and the plunger velocity. The extrusion is stopped when there is no more polymer in the barrel and the pressure at point $B$ is reported as the extrusion pressure. The pressure is determined by dividing the force applied by the piston on the billet by the cross-section of the barrel. The force is recorded on the chart as a function of time. As seen in Figure 2, the pressure increases rapidly, goes through a maximum and then decreases steadily after a short quick drop. The peak relates to the yield stress and the drop to the friction between the billet and the barrel as it will be discussed later (Chapter III-5).

Our goal is to produce flawless extrudates at the highest possible 
Figure 1. Extruder where

1 = Constant diameter region from A to B.

2 = Cone region of decreasing diameter from B to C. Cone angle $20^{\circ}$.

3 = Capillary region of constant diameter from C to D. 


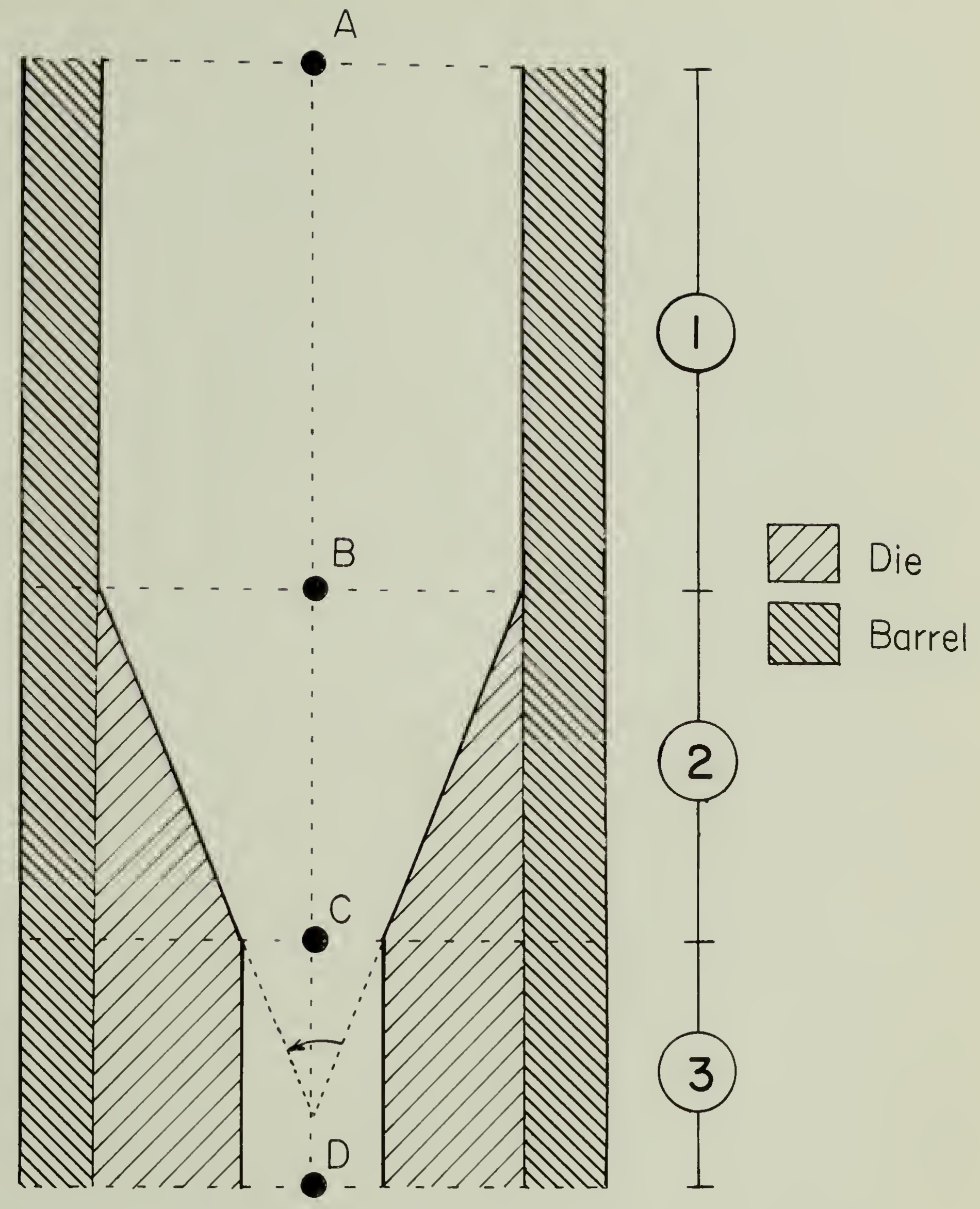

Figure 1 


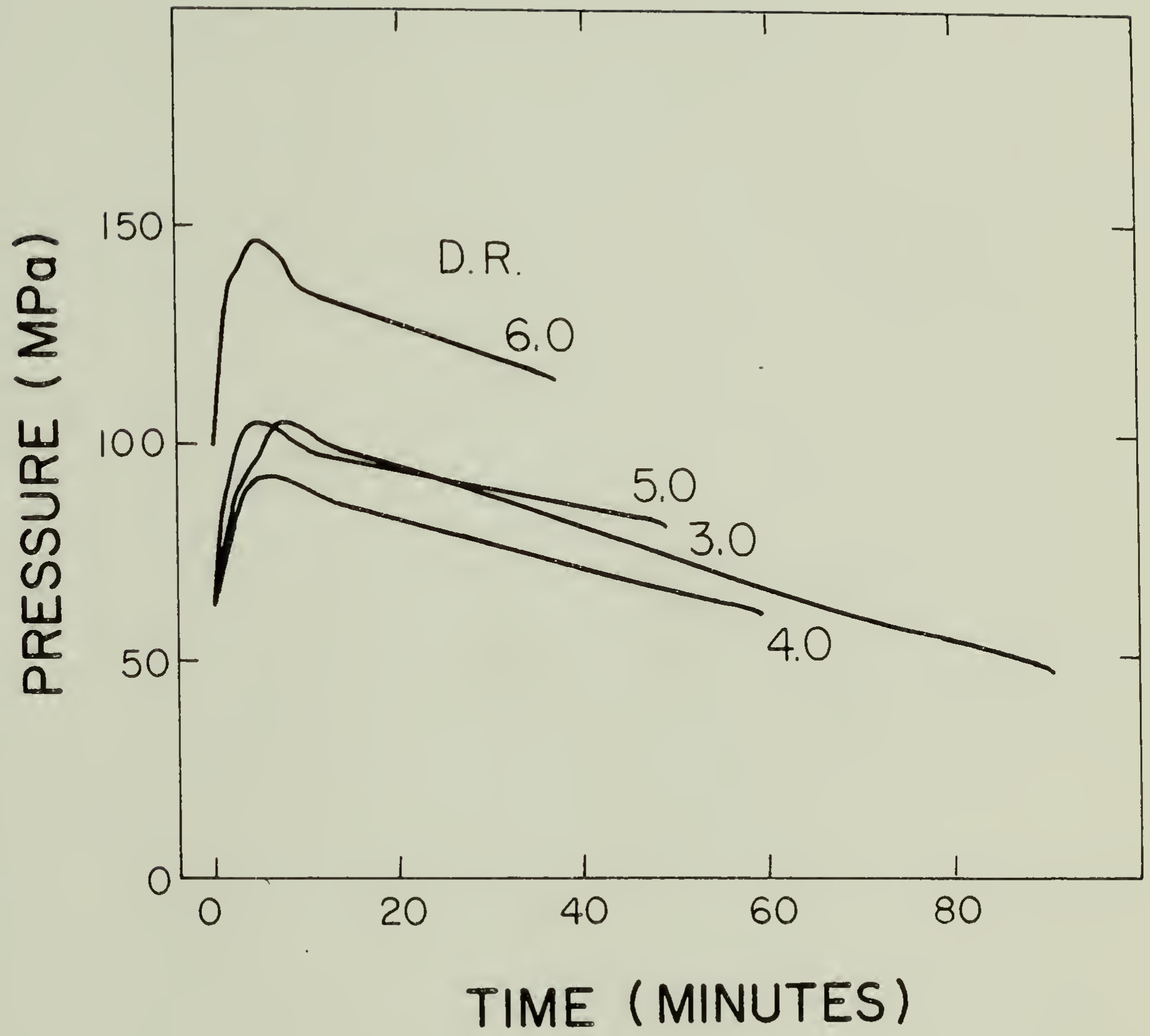

Figure 2. Recorded pressure as a function of extrusion time for sample C. $\mathrm{T}_{\mathrm{ex}}=40^{\circ} \mathrm{C}$ and $\mathrm{plunger}$ velocity $=0.1 \mathrm{~cm} / \mathrm{min}$. 
draw ratios (DR) for the extrusion temperatures studied. At high draw ratio, the back pressure becomes so large that instabilities take place, giving rise to irregularities in the extrudates. To lower the pressure, the plunger velocity, the controlling variable, is reduced. Tables 3 5 show the plunger velocities for the three polymers over the temperature range studied. Figures $3-5$ show the extrusion pressure as a function of strain but they include only data performed at the same velocity for each polymer. The draw ratio is related to strain by Equation 3 where $l$ and $l o$ are the lengths of respectively the extrudate and the billet:

$$
\text { Strain } \varepsilon=\operatorname{Ln} \frac{\ell}{\ell_{0}}=\operatorname{LnDR}
$$

Table 3

Plunger Velocity for Sample A Extrusion ( $\mathrm{cm} / \mathrm{min})$

\begin{tabular}{llllll}
\hline $\begin{array}{l}T_{e x} \\
\left({ }^{0} \mathrm{C}\right)\end{array}$ & 3.0 & $\begin{array}{l}\text { Draw Ratio } \\
4.0\end{array}$ & 5.0 & 6.0 & 7.0 \\
\hline 22 & 0.02 & 0.02 & 0.02 & 0.01 & 0.005 \\
40 & 0.02 & 0.02 & 0.02 & 0.02 & 0.005 \\
60 & 0.02 & 0.02 & 0.02 & 0.02 & 0.005 \\
80 & 0.02 & 0.02 & 0.02 & 0.02 & 0.005 \\
\hline
\end{tabular}


Table 4

Plunger Velocity for Sample B Extrusion ( $\mathrm{cm} / \mathrm{min}$ )

\begin{tabular}{lllllll}
$\begin{array}{l}T_{\text {ex }} \\
\left({ }^{\circ} \mathrm{C}\right)\end{array}$ & 3.0 & 4.0 & 5.0 & 6.0 & 7.0 & 8.0 \\
\hline 27 & 0.1 & 0.1 & 0.1 & 0.1 & 0.005 & - \\
40 & 0.1 & 0.1 & 0.1 & 0.1 & 0.005 & -- \\
60 & 0.1 & 0.1 & 0.1 & 0.1 & 0.005 & -- \\
80 & 0.1 & 0.1 & 0.1 & 0.1 & 0.005 & 0.005 \\
\hline
\end{tabular}

Table 5

Plunger Velocity for Sample C Extrusion (cm/min)

\begin{tabular}{llllllll} 
Tex & \multicolumn{7}{c}{ Draw Ratio } \\
$\left({ }^{\circ} \mathrm{C}\right)$ & 3.0 & 4.0 & 5.0 & 6.0 & 7.0 & 8.0 & 9.0 \\
\hline 27 & 0.1 & 0.1 & 0.1 & 0.1 & 0.005 & 0.005 & --- \\
40 & 0.1 & 0.1 & 0.1 & 0.1 & 0.01 & 0.005 & --- \\
60 & 0.1 & 0.1 & 0.1 & 0.1 & 0.1 & 0.005 & -- \\
80 & 0.1 & 0.1 & 0.1 & 0.1 & 0.1 & 0.005 & 0.005 \\
\hline
\end{tabular}


Figures 3 - 5 show an increase of extrusion pressure with the strain. This increase is particularly steep at low temperatures. The same trend has been observed during hydrostatic extrusion of 1 inear PE by Cappaccio et $a 1.18$ and by Takayanagi ${ }^{19}$ who interpreted it as a strain hardening phenomenon. Strain hardening is an indication of the change in polymer structure from lamellar to fibrillar. Hence, more strain hardening means that more crystal bridges or tie molecules are formed during plastic deformation. ${ }^{19}$ Strain hardening was also shown by Mead and Porter ${ }^{5}$ for solid-state extrusion of HDPE in terms of increasing elongational viscosity with draw ratio. The die pressure drop $\Delta P=P_{B}-P_{D}$, where $P_{B}$ and $P_{D}$ are the pressures at points $B$ and $D$ respectively (Figure 1), may be expressed as the sum of two components: ${ }^{20} \Delta \mathrm{P}_{\mathrm{SH}}$ a component due to strain hardening and $\Delta \mathrm{P}_{\mathrm{SR}}$ a component due to viscous resistance of the polymer (Equation 4). At lower temperatures, the deformation efficiency is higher, i.e. 1ess viscous dissipation, and strain-hardening sets in earlier.

$$
\Delta \mathbf{P}=\Delta \mathbf{P}_{\mathrm{SH}}+\Delta \mathrm{S}_{\mathrm{R}}
$$

From the same figures, it can be seen that the linear low density polyethylenes ( $B$ and $C$ ) draw more easily than the one with long branches (A). The extrusion velocities for the former are five times higher than that for the latter with the extrusion pressures of the same order. Long chain branching probably accounts for this large difference since the crystalinity is the same in $A$ and $B$, i.e. same short chain 


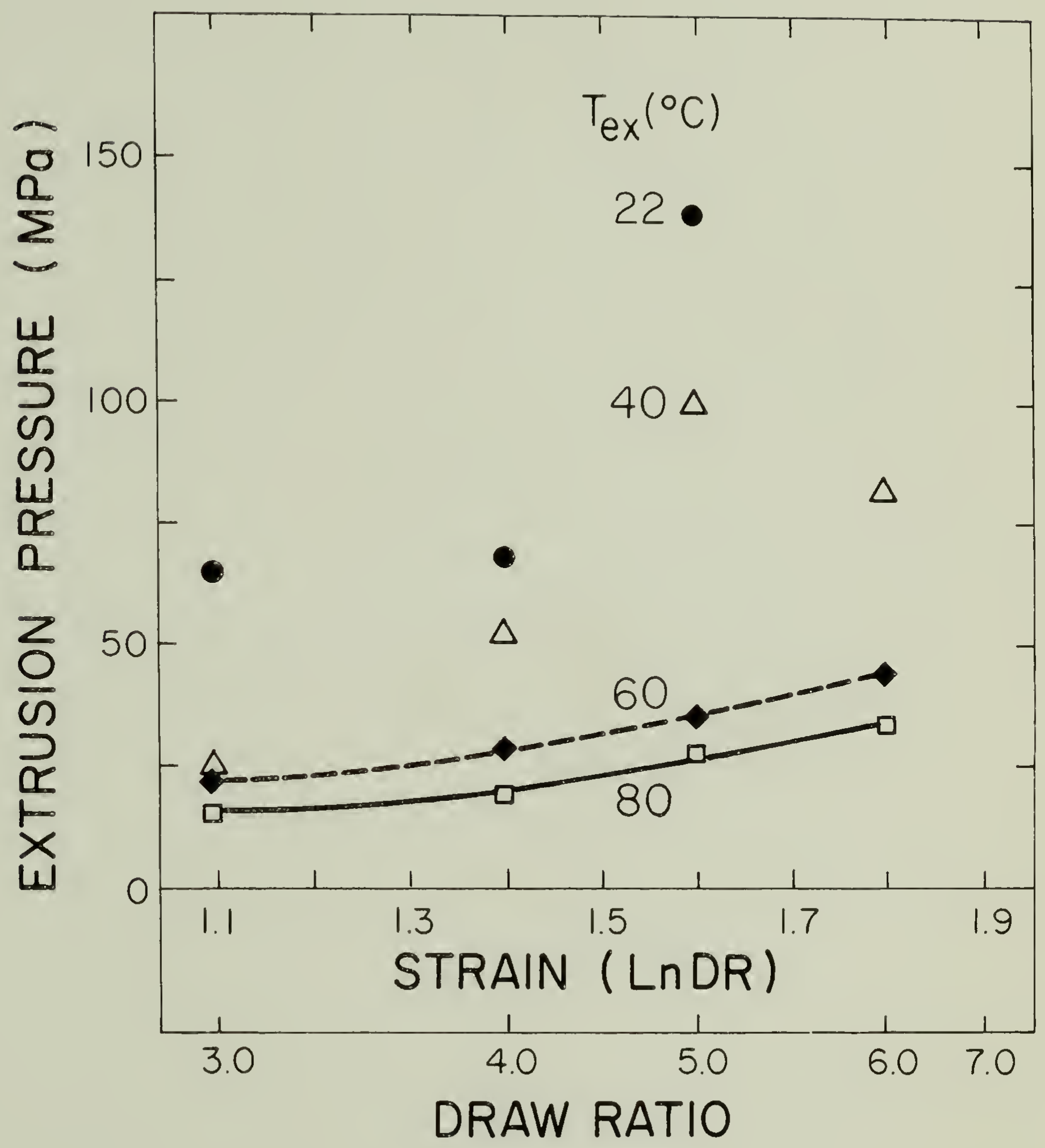

Figure 3. Sample A extrusion pressure versus strain at the extrusion temperatures as shown. 


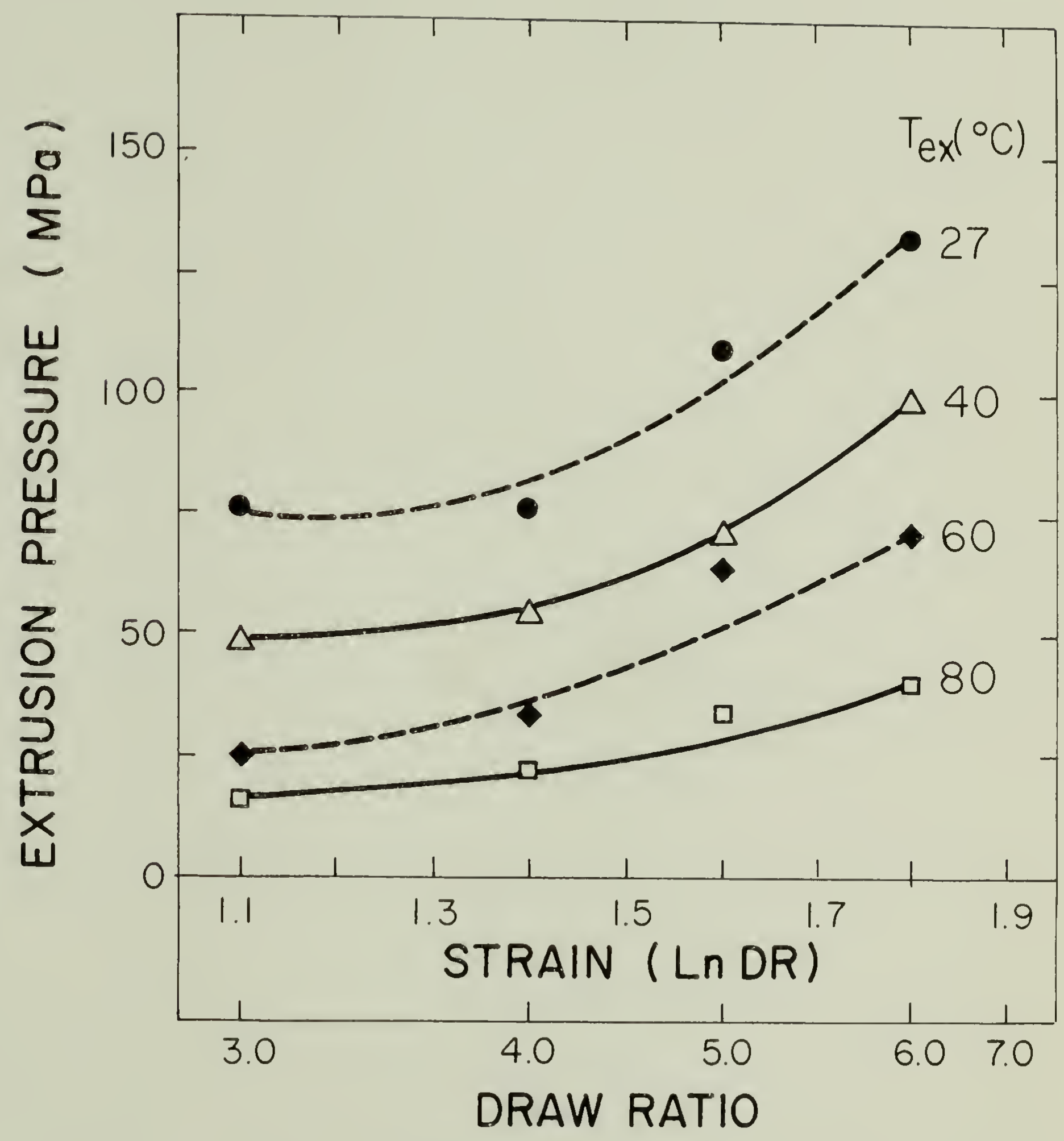

Figure 4. Sample B extrusion pressure versus strain at the extrusion temperatures as shown. 


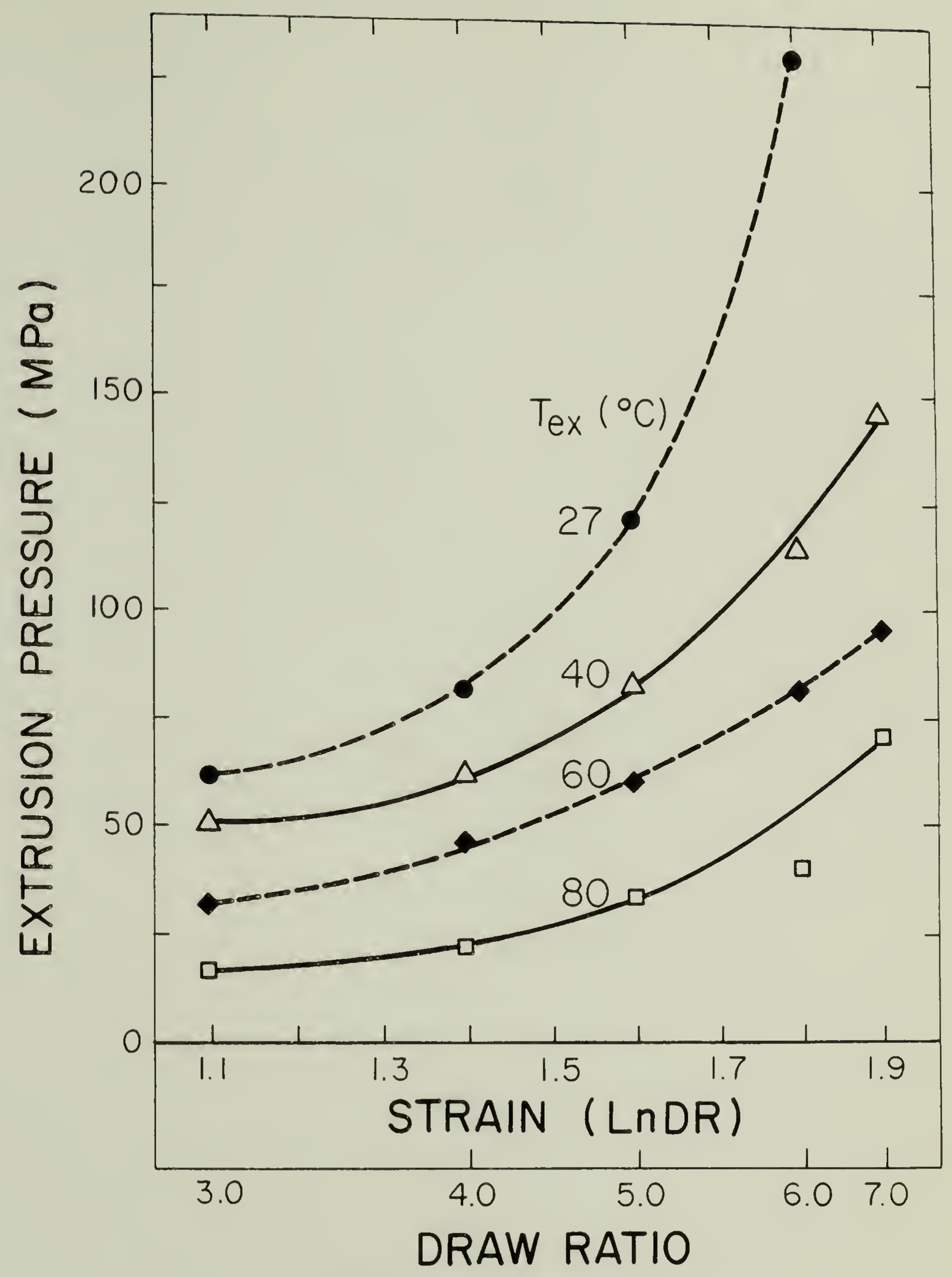

Figure 5. Sample C extrusion pressure versus strain at the extrusion temperatures as shown. 
branching content, and the molecular weight is lower in the former $(32,000$ and 36,000 respectively). Higher drawability of the linear LDPE compared to the long branched LDPE is also observed in cold-drawing and attributed to the much shorter branches in the former. 21

It can also be seen that polymer C strain-hardens more readily than B of lower crystallinity $(59 \%$ and $49 \%$ respectively), i.e. of higher short branches content, but of higher molecular weight $(34,000$ and 36,000 respectively). Both large side groups and molecular weights reduce plastic deformation roles. ${ }^{22}$ Consequently, the transformation from lamellar to fiber structure takes place more readily in $C$ than in $B$ thus explaining the more rapid strain-hardening in the former. It could also be due partly to an easier unfolding of a more regular lamellar structure. ${ }^{18,19}$ However, Mead and Porter ${ }^{5}$ show that the elongational viscosity increases much faster, i.e. strain-hardening is more rapid, at higher molecular weight. We are inclined to think that the apparent contradiction stems from the fact that at higher MW's, the role of the amorphous component is more important and molecular entanglements become the predominant feature. ${ }^{18}$ Therefore, the more rapid strain-hardening reported by Mead and Porter ${ }^{5}$ most 1 ikely reflects the resistance to draw due to more entanglements. Indeed, the drawing behavior of ultra high molecular weight polymers is the limiting case in which the overriding factor is the deformation process of the amorphous component. ${ }^{18}$ On the other hand, the behavior observed in our polymers must reflect the difference in rates of morphological changes. 


\section{Extrudate Qua1ity}

The quality of the extrudate is described in Tables $6-8$. The quality is described as the following:

(i) Very good (VG) means that the extrudate is smooth and flawless.

(ii) Good (G) describes a straight extrudate that has only slight flaws such as an occasional surface crack which do not affect its overa11 good shape.

(iii) Distorted (D) indicates more severe and frequent surface cracks and/or a slightly wave-1ike shape for extrudate.

(iv) Fracture (F) describes a fragile sample with continuous crack (not 1imited to the surface) that propagates helicoidally at $45^{\circ}$.

Tab le 6

Sample A Extrudate Quality

\begin{tabular}{ccccccc}
\hline $\begin{array}{c}T_{\text {ex }} \\
\left({ }^{\circ} \mathrm{C}\right)\end{array}$ & 3.0 & 4.0 & 5.0 & 6.0 & 7.0 \\
\hline 22 & VG & VG & G & D & F \\
40 & VG & VG & VG & G & F \\
60 & VG & VG & VG & VG & D \\
80 & VG & VG & VG & VG & D \\
\hline
\end{tabular}

VG = Very Good; $G=$ Good; $D=$ Distorted; $F=$ Fracture. 
Table 7

Sample B Extrudate Quality

\begin{tabular}{cccccccc}
\hline $\begin{array}{c}T_{\text {ex }} \\
\left({ }^{\circ} \mathrm{C}\right)\end{array}$ & 3.0 & 4.0 & 5.0 & 6.0 & 7.0 & 8.0 \\
\hline 27 & VG & VG & VG & VG & D & - \\
40 & VG & VG & VG & VG & D & - \\
60 & VG & VG & VG & VG & VG & - \\
80 & VG & VG & VG & VG & VG & D \\
\hline
\end{tabular}

Table 8

Sample C Extrudate Quality

\begin{tabular}{|c|c|c|c|c|c|c|c|}
\hline${ }^{T}$ (gx) & \multicolumn{7}{|c|}{ Draw Ratio } \\
\hline 27 & VG & VG & VG & VG & G & D & - \\
\hline 40 & VG & VG & VG & VG & G & G & - \\
\hline 60 & VG & VG & VG & VG & VG & G & - \\
\hline 80 & VG & VG & VG & VG & VG & G & D \\
\hline
\end{tabular}

$V G=$ Very Good; $G=$ Good; $D=$ Distorted; $F=$ Fracture. 
The onset of flaws in extrudate is usually accompanied by instabilities in the pressure which starts fluctuating in a sinusoidal fashion. The more pronounced the fluctuations and the more severe the flaws in the extrudate. Photographs $1-3$ show extrudates of all polymers obtained at an extrusion temperature of $80^{\circ} \mathrm{C}$. One can see the increase in transparency with DR. This probably indicates a higher orientation of the crystals at higher draw ratio. Of course, it is also due to the fact that as the diameters get smaller with draw, they become more transparent. The first hypothesis is demonstrated by cutting small cylinders of same length cross-sectionally from the extrudates and by looking through them in the draw direction. This shows unequivocally that transparency increases a great deal with draw independently from thickness. It must be noted that aside from the cracks, the fractured extrudate is transparent meaning probably that high orientation is still present in the nonfractured part of the sample.

If a satisfactory extrusion is considered to produce at least a Good (G) extrudate, then it can be said that polymers $A$, B and $C$ can be satisfactorily extruded in a single stage to draw ratios of respectively $6.0,7.0$ and 8.0 over the temperature range studied. Similar limitations have been observed for LDPE by Buckley and Long ${ }^{2}$ and Alexander and Worme $11 .^{3}$ Hope 22 in his study of hydrostatic extrusion of copolymers of linear PE points out that large butyl side groups, i.e. short chain branching, reduce plastic deformation. DeCandia et a $1^{23}$ offer an explanation of the low drawability of LDPE based on the Peter1in mode1: as previously stated, 23 it is the large number of tie 
Plate 1. Sample A Extrudates. $T_{e x}=80^{\circ} \mathrm{C}$. 
$D R=7.0$

:

$\infty$

$D R=6.0$

II

$\begin{array}{lll}0 & 0 & \\ & \text { N } & 0 \\ & 0 & 0\end{array}$

$D R=5.0$

$\begin{array}{lll}E & \lambda \\ E & \frac{1}{10} \\ E & 0 & 0\end{array}$

$D R=4.0$

$-$

ㅁ.

$D R=3.0$ 
P1ate 2. Sample B Extrudates. $T_{\text {ez }}=80^{\circ} \mathrm{C}$. 


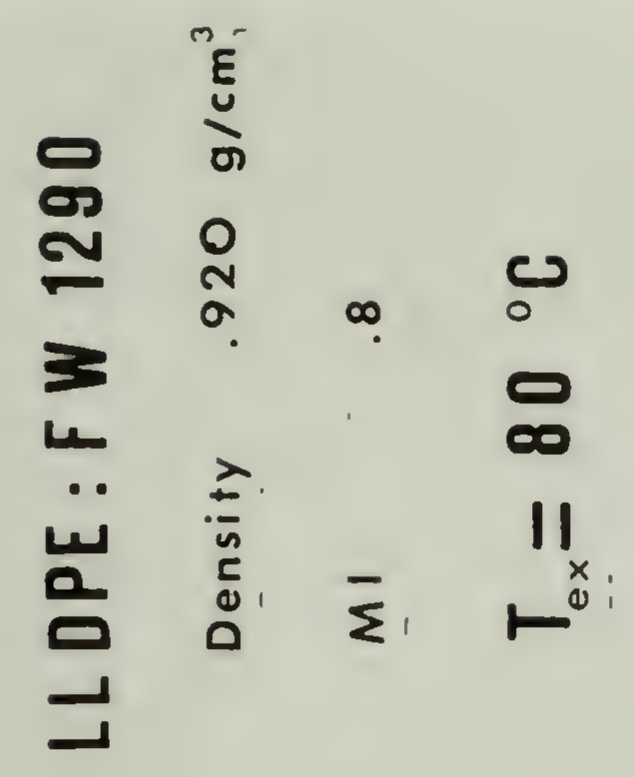

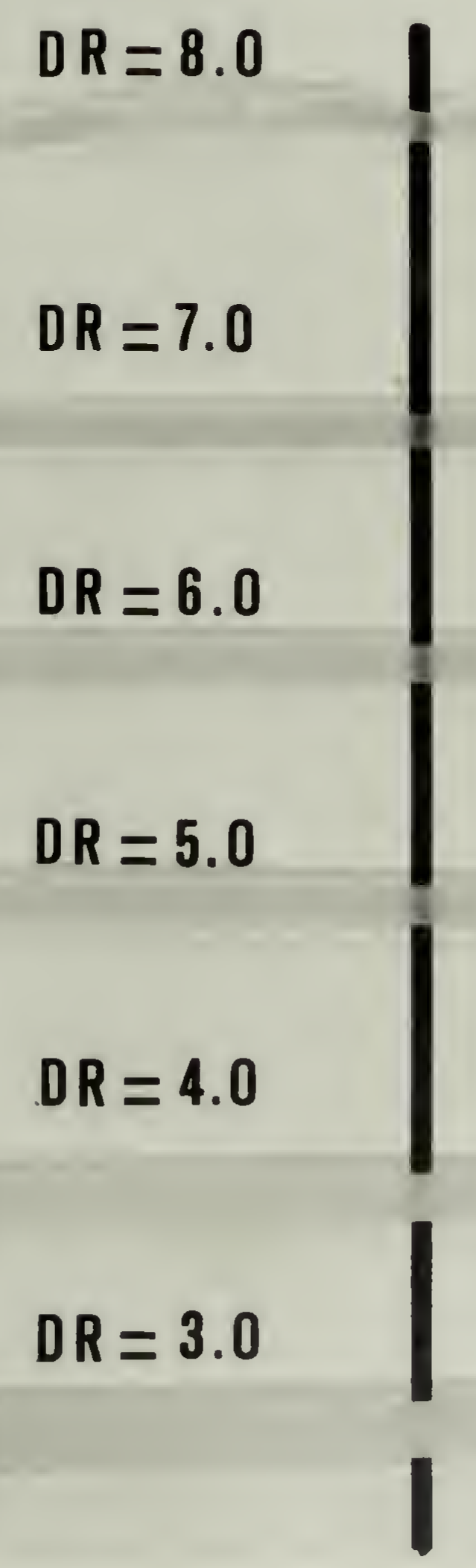


Plate 3. Sample C Extrudates. $T_{e x}=80^{\circ} \mathrm{C}$. 


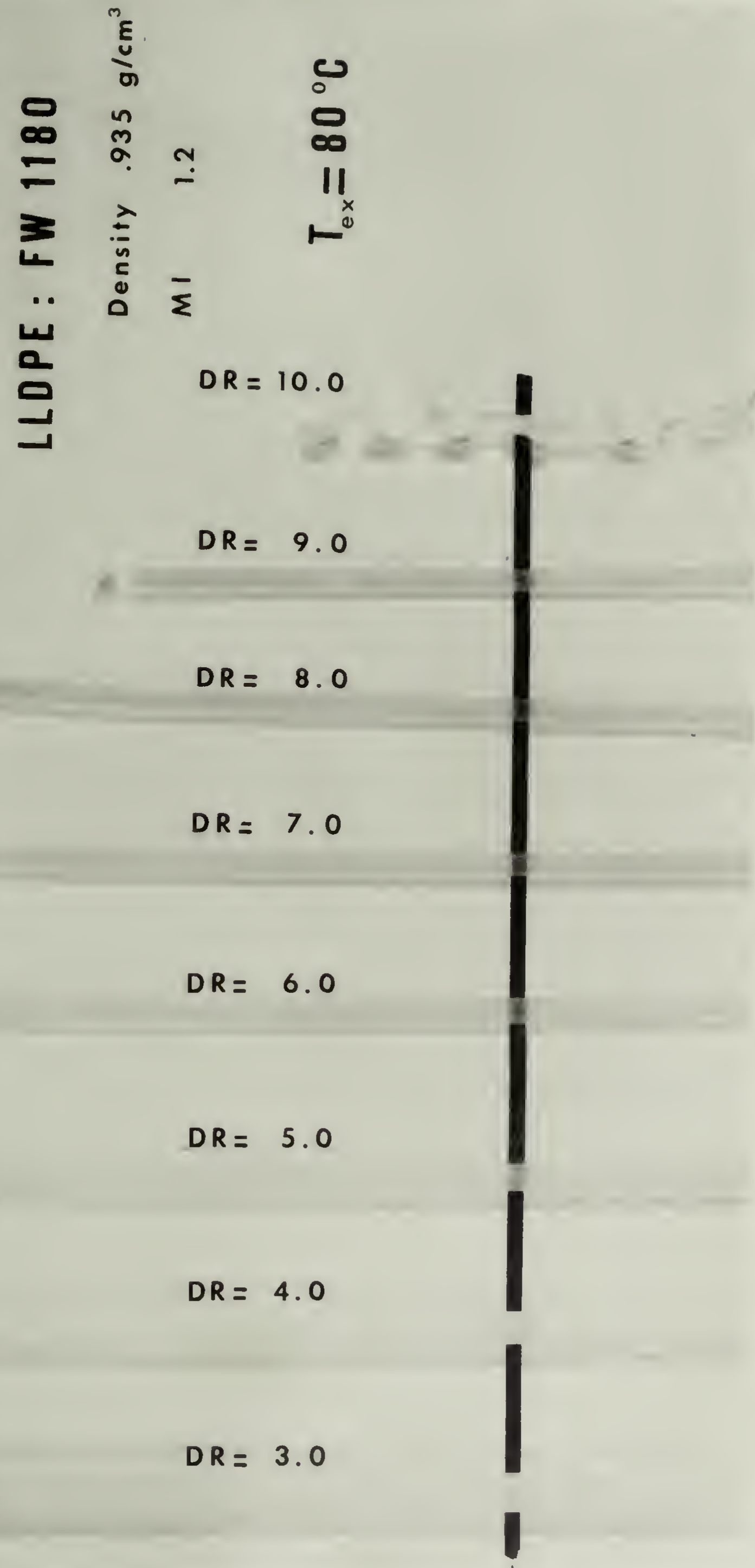


molecules which on the one hand yields the large amorphous component and on the other hand prevents drawing beyond a relatively sma11 DR if they connect different stacks of parallel lamellae.

Alexander and Worme $11^{3}$ attribute the cracks observed to me $1 t$ fracture. Hope 24 concludes that the instabilities are caused by partial me1ting. The two authors explain this by a temperature rise due to heat of deformation. According to equation 5 used by the former, an extrusion pressure of $100 \mathrm{MPa}$ would translate into an adiabatic temperature rise of almost $50^{\circ} \mathrm{C}$. Equation 5 is expressed as following:

$$
\Delta \mathrm{T}=3.27 \times 10^{-3} \mathrm{P}{ }^{\circ} \mathrm{C}
$$

where $\Delta \mathrm{T}$ is the temperature $\mathrm{r}$ ise in $\left({ }^{\circ} \mathrm{C}\right)$ and $\mathrm{P}$ the extrusion pressure in psi. Indeed, partial melting was observed visually during extrusion of polymers $A$ and $B$ at $80^{\circ} \mathrm{C}$. Polymer melt leaked into the clearance between the die and the holder. However, Hope 24 reports the existence of two distinct regimes depending on extrusion velocity: isothermal and adiabatic. He shows that the process is isothermal at production rates of less than $10 \mathrm{~mm} \mathrm{~min}^{-1}$. The maximum speeds used in this study do not exceed $0.2 \mathrm{~mm} \mathrm{~min}^{-1}$ for polymer $A$ and $1 \mathrm{~mm} \mathrm{~min}^{-1}$ for $B$ and $C$. Moreover, the fractured samples occurred on extrusion at the lowest speed, $0.05 \mathrm{~mm}$ min $^{-1}$, at which Equation 5 would not be applicable. Thus, temperature rise is unlikely a contributor. Moreover, extrudate expansion at the exit of the die (see next section on die swe11) would be larger than that observed for fractured samples $(\leq 10 \%)$ if these were in the melt 
state. Finally, if fracture occurred in the me1t state, orientation would be lost, thus resulting in non-transparent extrudates. Since the opposite is observed, fracture of the melt is unlikely to be the cause of the cracks observed especially at low temperatures. Instead, shear failure under compression is more likely the cause of these cracks.

\section{Extrudate Expansion}

The expansion of the extrudate at the exit of the die, or die swe 11,25 is defined as follows:

D.S. $(\%)=\frac{d-d_{0}}{d_{0}} \times 100 \%$

where $d$ and $d_{0}$ are the diameters of the extrudate and the die capillary respectively. Die swe11 as a function of temperature is plotted in Figures $6-8$ for extrusions performed at the same speed.

Die swe 11 is a measure of the recovery of the elastic energy stored in both the capillary and its entrance zone. ${ }^{26}$ Since this expansion occurs below the melting point and above $T_{g}$, die swell represents then the elastic recovery of the amorphous component only. Therefore, die swe11 in solid-state extrusion is small as compared to that in melt extrusion. Thus, the amount of die swe11 depends on the mobility of the amorphous chains, i.e. their ability to shrink back under ambient pressure and extrusion temperature.

It can be seen from the figures that die swell for samples $A$ and $B$ 


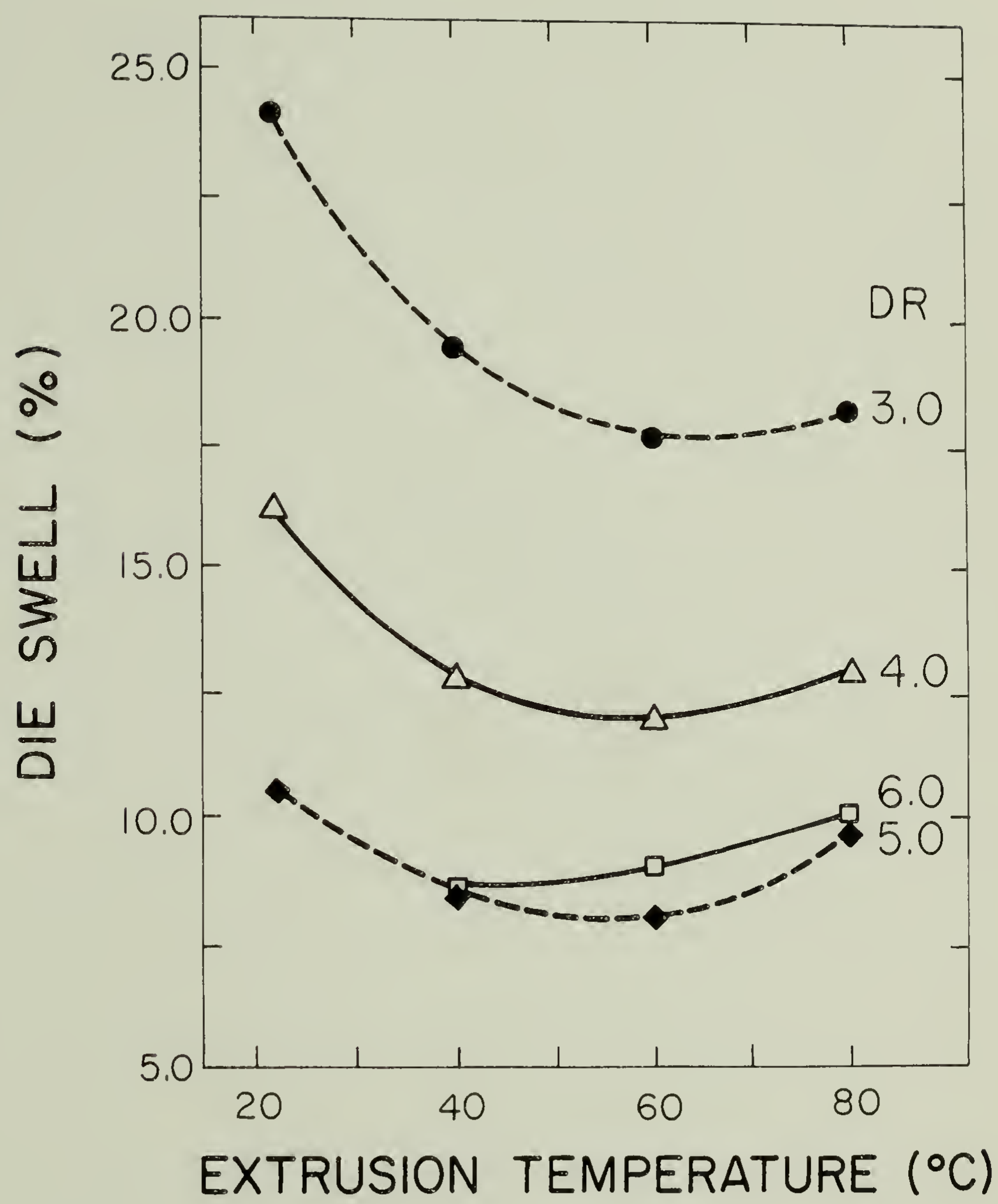

Figure 6. Extrudate die swell for sample A versus extrusion temperature for the draw ratios as shown. 


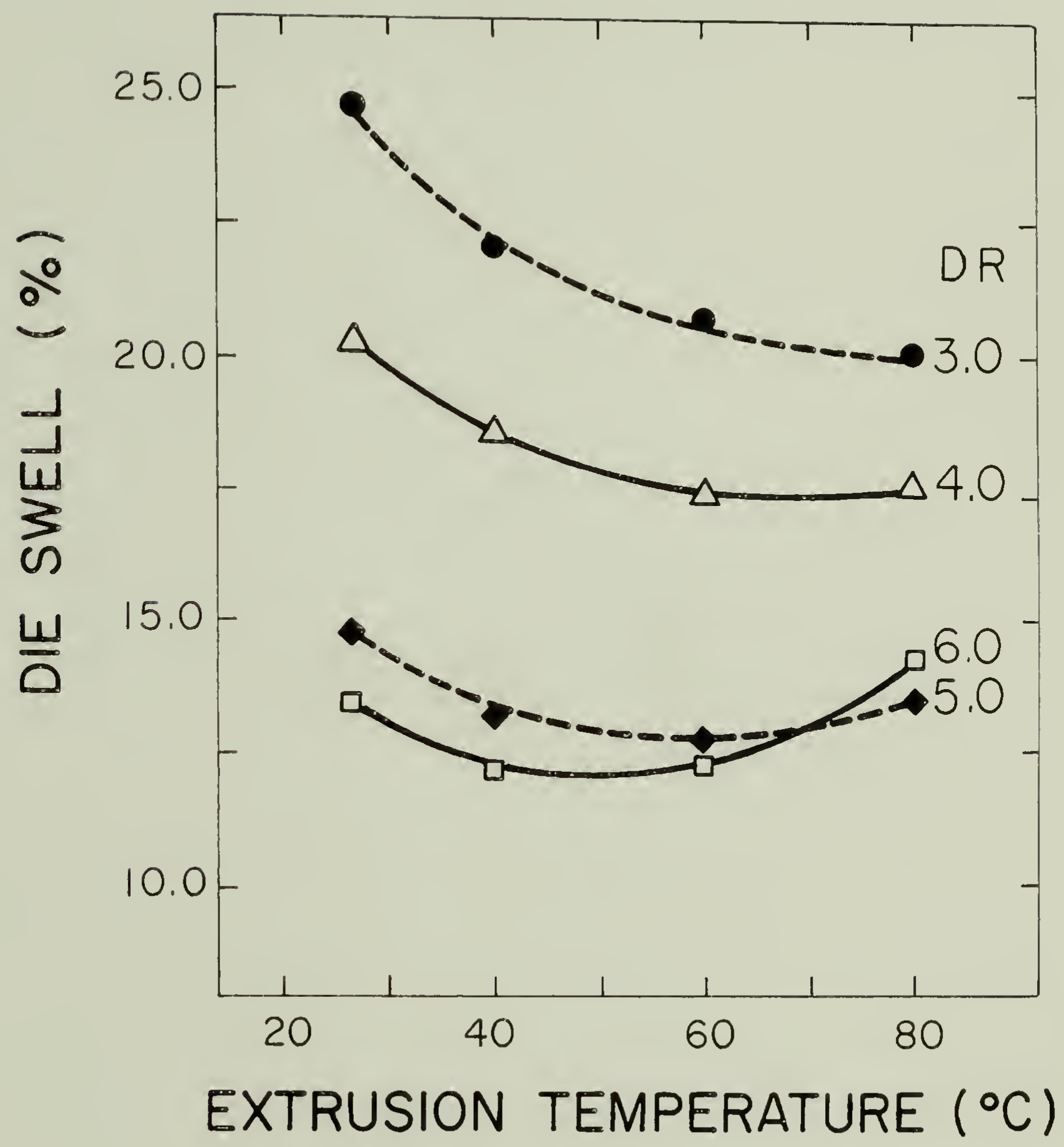

Figure 7. Extrudate die swell for sample B versus extrusion temperature for the draw ratios as shown. 


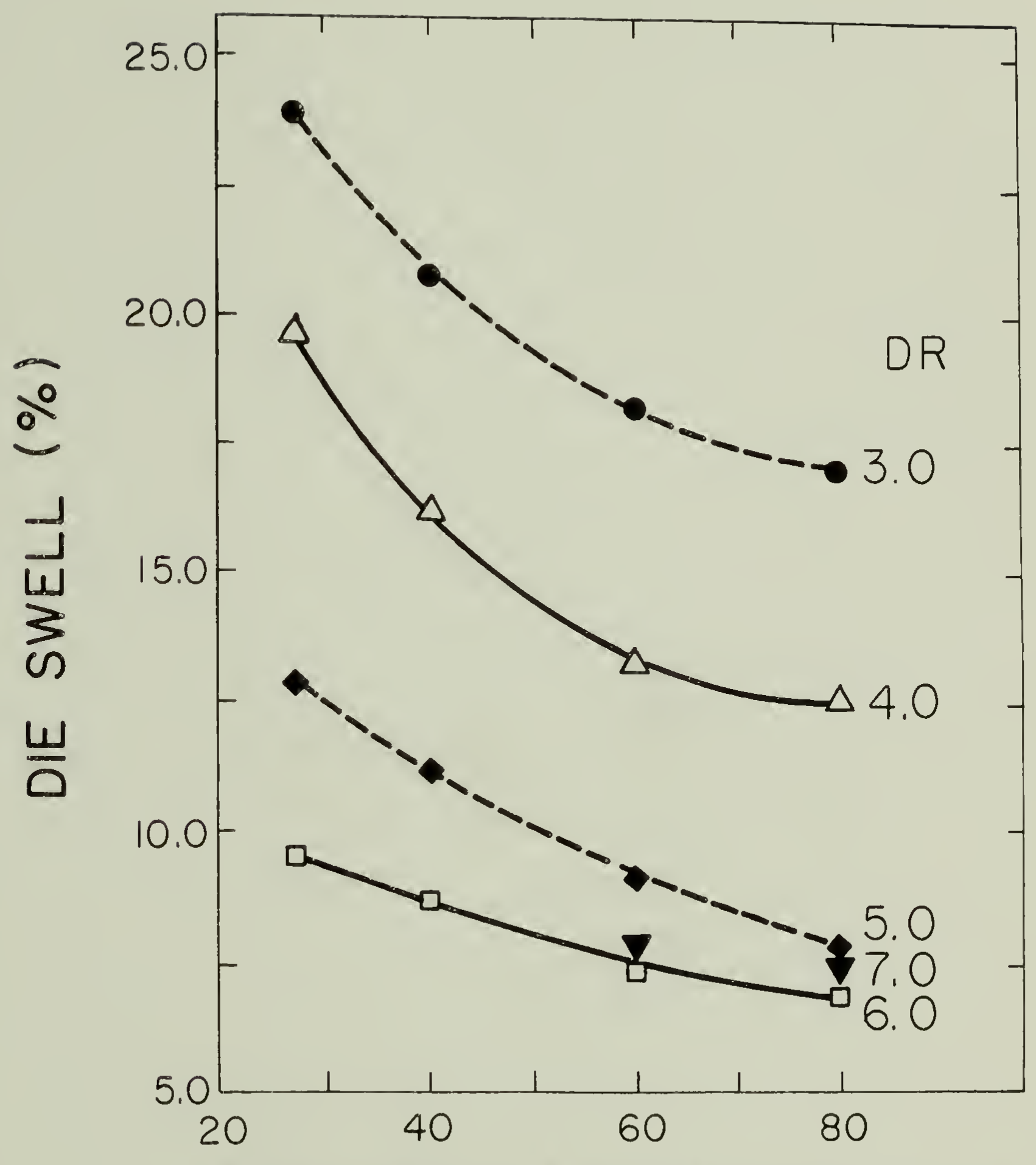

EXTRUSION TEMPERATURE $\left({ }^{\circ} \mathrm{C}\right)$

Figure 8. Extrudate die swell for sample C versus extrusion temperature for the draw ratios as shown. 
goes through a minimum with increasing extrusion temperature whereas for $C$ it simply decreases over the range studied. The same behavior as that of $A$ and $B$ is observed by Alexander and Worme $11^{3}$ for LDPE. This behavior may be the result of two competing effects: the increased mobility of the chains on the one hand and the reduced deformation efficiency on the other hand. As the fraction of the energy input that is used to extend and orient the chains, i.e. deformation efficiency, is reduced at higher temperature 6,26 the amount of elastic energy stored will decrease resulting in less elastic recovery. The temperature dependence of die swe 11 can be divided into two regions: below and above the temperature of minimum swe11. Thus, deformation and chain mobility are each the determining factor in the first and second regions respective $1 y$.

Below the temperature of minimum swe11, elastic recovery decreases with increasing draw ratio. Similar observations have been made on both $10 w^{2}$ and high ${ }^{24}$ density PE. In the drawn polymer, the tie molecules are taut and tend to relax upon release of the stress at the exit of the die. However, their mobility is more efficiently blocked as the draw ratio increases. DeCandia et a 1.27 suggest an increase of the $\mathrm{T}_{\mathrm{g}}$ of the tie molecules which would be then in a frozen-in-state. Others 28,29 attribute the decrease in mobility to higher content in continuous crystals 6,30 which, in u1tra-drawn polymers, would allow no die swe11 at a11.24,29 Continuous crystals are just the 1 imit of taut tie molecules in the Peterlin mode $1^{7,31}$ or just folded-chain crystals in the fiber which are connected to each other and as such lock in the amorphous component. 15 
Low density polyethylene being polydisperse and thus probably containing low molecular weight components, the melting peak of the original billet is broad. Consequently, the temperature of minimum die swell may be related to the onset of melting in the undrawn material. In other words, it is the increased mobility of the tie molecules due to partial melting that causes the increase of die swell with temperature. This would explain why die swell for polymer $C$, which has a higher melting point $\left(\sim 127^{\circ} \mathrm{C}\right)$, does not go through a minimum over the temperature range studied. A decrease in the minimum die swell temperature with increasing DR is observed for polymers $A$ and $B$. The shift is $\leq 10^{\circ} \mathrm{C}$ going from $\mathrm{DR}=3.0$ to 5.0 for the former and $30^{\circ} \mathrm{C}$ going from 3.0 to 6.0 for the latter (Table 9). At present, the only possible explanation is that it is due to a temperature rise caused by heat of deformation as suggested by Alexander and Worme $11^{3}$ for the behavior observed. However, that contradicts the previous statement concerning isothermal regime and the subsequent insignificant temperature rise (section III-2). In any case, let one assume that there is some temperature rise. Heat of deformation is proportional to the tensile viscosity $\eta_{a}$ and to the square of the deformation rate $\dot{\gamma}^{26}$

$$
\text { Total energy rate }=\eta_{a} \dot{\gamma}^{2}
$$

The deformation rate $(\dot{\gamma}=d L / L d T)$ increases with extrusion rate (dL/dT). Therefore, when the draw ratio is increased, both the viscosity (strain-hardening) and the deformation rate induce a 
substantial rise in temperature. Subsequently, at a higher draw ratio, the temperature of melting is reached earlier. Although the viscosity of A may be larger, i.e. lower drawability than that of $B$, the deformation rate of the latter is much larger than that of the former, i.e. extrusion rate five times larger. Since the total energy is proportional to the square of the deformation rate, this is consistent with the temperature $r$ ise for $B$ being about as twice as large as that for $B$.

\section{Table 9}

Minimum Die Swe 11 Temperature $\left({ }^{\circ} \mathrm{C}\right)$

\begin{tabular}{ccccc} 
Po1yme r/DR & 3.0 & 4.0 & 5.0 & 6.0 \\
\hline A & 65 & $57-58$ & $54-55$ & - \\
B & 78 & 68 & 58 & $49-50$ \\
\hline
\end{tabular}

\section{Extrusion Draw Ratios}

The nominal draw ratio, i.e. die draw ratio (DR), is usually larger than the effective draw ratio, that is extrusion draw ratio (EDR), because of die swe11. The latter is a loss of orientation. Therefore, since we want to correlate extrudate properties to the actual extent of deformation, all measured properties will be reported as a function of EDR instead of DR. EDR can be determined (Equation 8) either by the ratio of cross-sections of the billet and the extrudate (Tables $10-12$ ) 
or by the ratio of the plunger and the extrudate velocities. Assuming volume conservation on draw, one can write:

$$
\operatorname{EDR}=\frac{\mathrm{D}_{\mathrm{o}}^{2}}{\mathrm{D}^{2}}=\frac{\mathrm{L}}{\mathrm{L}_{\mathrm{o}}}=\frac{\mathrm{L} / \mathrm{t}}{\mathrm{L} / \mathrm{t}}=\frac{\mathrm{v}}{\mathrm{v}_{\mathrm{o}}}
$$

where $L_{0}, D_{0}$ and $v_{0}$ represent the length, the diameter and the velocity respectively of the billet, $L, D$ and $v$ those of the extrudate and $t$ the extrusion time. Let $E D R^{*}$ be the draw ratio calculated from the rates and EDR that from the cross-sections. From Tables $13-15$, it can be seen that EDR* $\geq E D R$.

Table 10

EDR for Sample A

\begin{tabular}{llllll}
$\begin{array}{c}\text { Tex } \\
\left(\begin{array}{l}\text { of } \\
\text { C }\end{array}\right.\end{array}$ & 3.0 & 4.0 & Draw Ratio & 7.0 \\
\hline 22 & 1.9 & 2.9 & 4.1 & 4.9 & 6.2 \\
40 & 2.1 & 3.1 & 4.1 & 4.9 & 6.2 \\
60 & 2.1 & 3.2 & 4.2 & 4.9 & 5.9 \\
80 & 2.2 & 3.0 & 4.1 & 4.8 & 5.6 \\
\hline
\end{tabular}

EDR = Extrusion Draw Ratio 
Table 11

EDR for Sample B

\begin{tabular}{|c|c|c|c|c|c|c|}
\hline$\left.T_{\left(\delta^{x}\right.}{ }_{C}\right)$ & 3.0 & 4.0 & $5.0^{\mathrm{D}}$ & $\begin{array}{r}\text { atio } \\
6.0\end{array}$ & 7.0 & 8.0 \\
\hline 27 & 1.9 & 2.7 & 3.7 & 4.5 & 5.4 & $\ldots$ \\
\hline 40 & 2.0 & 2.8 & 3.8 & 4.6 & 5.6 & - \\
\hline 60 & 2.0 & 2.8 & 3.9 & 4.7 & 5.6 & -- \\
\hline 80 & 2.0 & 2.8 & 3.8 & 4.5 & 5.5 & 6.4 \\
\hline
\end{tabular}

Table 12

EDR for Sample C

\begin{tabular}{llllllll}
$\begin{array}{c}T_{\text {ex }} \\
\left({ }^{\circ} \mathrm{C}\right)\end{array}$ & 3.0 & 4.0 & 5.0 & 6.0 & 7.0 & 8.0 & 9.0 \\
\hline 27 & 1.9 & 2.7 & 3.9 & 4.9 & 5.8 & 6.7 & $\ldots$ \\
40 & 2.0 & 2.9 & 3.9 & 4.9 & 5.9 & 6.8 & $\ldots$ \\
60 & 2.1 & 3.1 & 4.1 & 5.0 & 5.9 & 6.9 & $\ldots$ \\
80 & 2.2 & 3.1 & 4.2 & 5.1 & 5.9 & 6.9 & 7.6 \\
\hline
\end{tabular}

EDR = Extrusion Draw Ratio 
Table 13

(EDR*-EDR) for Sample A

\begin{tabular}{ccccc}
\hline$T_{\text {ex }}$ & \multicolumn{3}{c}{ Draw Ratio } \\
$\left({ }^{\circ} \mathrm{C}\right)$ & 3.0 & 4.0 & 5.0 & 6.0 \\
\hline 22 & 0.2 & 0.2 & 0.5 & 0.5 \\
40 & 0.0 & 0.1 & 0.4 & 0.3 \\
60 & 0.1 & 0.1 & 0.0 & 0.2 \\
80 & 0.0 & 0.0 & 0.0 & 0.0 \\
\hline
\end{tabular}

Table 14

(EDR*-EDR) for Sample B

\begin{tabular}{ccccc}
\hline$T_{\text {ex }}$ & \multicolumn{3}{c}{ Draw Ratio } \\
$\left({ }^{\circ} \mathrm{C}\right)$ & 3.0 & 4.0 & 5.0 & 6.0 \\
\hline 27 & 0.2 & 0.3 & 0.4 & 0.4 \\
40 & 0.1 & 0.2 & 0.3 & 0.4 \\
60 & 0.1 & 0.1 & 0.2 & 0.1 \\
80 & 0.0 & 0.0 & 0.0 & 0.0 \\
\hline
\end{tabular}


Table 15

(EDR*-EDR) for Sample C

\begin{tabular}{llllll}
$\begin{array}{c}\mathrm{T}_{\text {ex }} \\
\left.{ }^{\circ} \mathrm{C}\right)\end{array}$ & 3.0 & 4.0 & 5.0 & 6.0 & 7.0 \\
\hline 27 & 0.3 & 0.4 & 0.4 & 0.4 & - \\
40 & 0.2 & 0.2 & 0.4 & 0.4 & -- \\
60 & 0.1 & 0.1 & 0.2 & 0.3 & 0.3 \\
80 & 0.0 & 0.0 & 0.1 & 0.2 & 0.3 \\
\hline
\end{tabular}

To keep the strand straight during extrusion a small weight is hung onto it. EDR* is determined with the small weight hanging whereas EDR is determined without it. The small weight $(w=264 \mathrm{~g})$ develops a tensile stress on the extrudate of $7 \mathrm{kPa}$ for the 1 argest diameter, i.e. lowest DR, and $30 \mathrm{kPa}$ for the smallest diameter, i.e. highest DR. This stress is negligible in comparison with the extrusion pressure but may be sufficient enough to draw the extrudate at the exit of the die to some extent thus creating some draw-down. Consequent1y, upon release of the tensile stress, some further swell may occur. This would explain the differences between EDR* and EDR. The general trend, though not regular, seems to be that the difference is larger at higher draw ratios and at lower extrusion temperatures which, it must be noted, are also conditions of more efficient deformation. 


\section{Coefficient of Friction}

The pressure drop observed in Figure 2 is due to the friction between polymer and barrel. To determine the coefficient of friction, one may use an equation derived by Tadmor and Gogos 32 for mechanical displacement flow of particulate solids compressed between two pistons at a constant speed in a straight channel of constant cross-section. Applied to a billet of initial length $L$ pushed through the barrel from point A to B (Figure 1), that equation becomes:

$$
\frac{P_{A}}{P_{B}}=e^{-2 \mu K L / R}
$$

where $P_{A}$ and $P_{B}$ are the pressures at points $A$ and $B$ respectively, $\mu$ the coefficient of friction, $R$ the radius of the barrel, and $K$, the ratio of radial to axial stress, a constant equal $1^{32}$ to 0.4 .

According to Equation 9, the axial pressure drops exponentially. As seen in Figure 2, it is most often not the case which may explain the scatter of the values of coefficient of friction of polymers $A, B$ and $C$ in Tables 16, 17 and 18 respectively. The friction coefficient also varies from one billet to another and particularly for sample A whose billets were sanded down. Nevertheless, the data shown in Tables 16 18 are on the whole reasonable. Hence, we may assume that, to a first approximation, the ratio between the maximum and extrusion, i.e. final, pressures is limited by the machine capabilities and by the risk of bending the plunger. Therefore, the larger maximum pressure for $D R=$ 
3.0 compared to that of $\mathrm{DR}=4.0$ (Figure 2) can be explained by the larger billet length of the former, i.e. 9.2 versus $6.0 \mathrm{~cm}$. In extrusion of HDPE at high draw, the pressure is apparently constant throughout extrusion. Indeed, because of the low coefficient of friction, Mead and Porter ${ }^{5}$ report a value of $\mu=0.01$, and the small length, the ratio $\mathrm{P}_{\mathrm{A}} / \mathrm{P}_{\mathrm{B}}$ becomes very small and subsequently the pressure drop becomes less noticeable. By spraying a polymer A billet with Teflon, it has been found that $P_{A} / P_{B} \sim 1$ at the scale of pressure used.

Table 16

Coefficient of Friction - Sample A

\begin{tabular}{ccccc}
\hline $\mathrm{T}_{\text {ex }}$ & \multicolumn{3}{c}{ Draw Ratio } \\
$\left({ }^{\circ} \mathrm{C}\right)$ & 3.0 & 4.0 & 5.0 & 6.0 \\
\hline 22 & 0.067 & 0.074 & 0.054 & -- \\
40 & 0.037 & 0.033 & 0.093 & 0.064 \\
60 & 0.049 & 0.071 & 0.100 & 0.025 \\
80 & 0.057 & 0.082 & 0.057 & 0.021 \\
\hline
\end{tabular}


Table 17

Coefficient of Friction - Sample B

\begin{tabular}{lccccc}
$\begin{array}{l}\mathrm{T}_{\text {ex }}^{(8 \mathrm{C}} \\
\mathrm{C}\end{array}$ & 3.0 & $\begin{array}{l}\text { Draw Ratio } \\
4.0\end{array}$ & 5.0 & 6.0 & 7.0 \\
\hline 27 & 0.069 & 0.040 & 0.059 & 0.029 & - \\
40 & 0.050 & 0.063 & 0.074 & 0.034 & -- \\
60 & 0.049 & 0.042 & 0.063 & 0.025 & 0.003 \\
80 & 0.037 & 0.036 & 0.035 & 0.029 & 0.038 \\
\hline
\end{tabular}

Table 18

Coefficient of Friction - Sample C

\begin{tabular}{|c|c|c|c|c|c|}
\hline $\left.\begin{array}{l}1 \\
(8 x \\
8\end{array}\right)$ & 3.0 & $\begin{array}{l}\text { Draw } \\
4.0\end{array}$ & Ratio & 6.0 & 7.0 \\
\hline 27 & 0.049 & 0.036 & 0.036 & 0.030 & 0.044 \\
\hline 40 & 0.048 & 0.041 & 0.028 & 0.038 & 0.023 \\
\hline 60 & 0.040 & 0.040 & 0.026 & 0.024 & 0.028 \\
\hline 80 & 0.036 & 0.036 & 0.037 & 0.029 & 0.027 \\
\hline
\end{tabular}




\section{PROPERTIES}

\section{Fractiona1 Crystallinity}

\subsection{From Density}

Using a two phase model, the degree of crystallinity is computed from density according to the following equation 33

$$
\begin{aligned}
& \mathbb{X}_{c}=\text { Crystallinity }(\%)=\frac{\rho c}{\rho} \cdot \frac{\rho-\rho a}{\rho c-\rho c} \times 100 \\
& \rho=\text { Measured density }\left(\mathrm{g} / \mathrm{cm}^{3}\right) \\
& \rho c=\text { Crystalline density }=1.000 \mathrm{~g} / \mathrm{cm}^{3(34)} \\
& \rho a=\text { Amorphous density }=0.855 \mathrm{~g} / \mathrm{cm}^{3(34)}
\end{aligned}
$$

The calculated fractional crystallinities of polymers $A, B$ and $C$ extrudates are shown in Tables $19-21$. The changes in overall apparent crystallinity are small, i.e. $\leq 4 \%$. According to Glenz, ${ }^{35}$ using the macroscopic density to determine the amount of crystallinity in drawn polymers may lead to erroneous results. In this regard, we decided to study the change of density instead of crystallinity upon extrusion. 
Table 19

Crystallinity (\%) from Density for Sample A

\begin{tabular}{lllllll}
$\begin{array}{c}T_{\text {ex }}^{(8)} \\
\mathrm{C})\end{array}$ & 1.0 & 3.0 & 4.0 & 5.0 & 6.0 & 7.0 \\
\hline 22 & 50.5 & 50.4 & 49.9 & 49.9 & 49.7 & 50.0 \\
40 & 50.5 & 50.1 & 49.8 & 49.8 & 49.9 & 50.1 \\
60 & 50.6 & 50.7 & 50.8 & 50.9 & 51.2 & 52 \\
80 & 50.7 & 51.0 & 51.2 & 51.6 & 52.0 & 53.0 \\
\hline
\end{tabular}

Table 20

Crystallinity (\%) from Density for Sample B

\begin{tabular}{|c|c|c|c|c|c|c|c|}
\hline$T_{(\varepsilon x}$ & 1.0 & 3.0 & 4.0 & $\begin{array}{c}\text { aw } R a t \\
5.0\end{array}$ & 6.0 & 7.0 & 8.0 \\
\hline 27 & 51.4 & 50.5 & 50.2 & 49.5 & 49.6 & 49.8 & -- \\
\hline 40 & 51.6 & 50.9 & 50.0 & 49.8 & 50.0 & 50.8 & -- \\
\hline 60 & 51.6 & 51.4 & 50.8 & 51.2 & 51.4 & 52.3 & -- \\
\hline 80 & 51.5 & 51.6 & 51.6 & 52.1 & 52.3 & 53.7 & 54.5 \\
\hline
\end{tabular}


Table 21

Crystallinity (\%) from Density for Sample C

\begin{tabular}{lllllllll}
$\begin{array}{c}\text { T ex } \\
\left({ }^{\circ} \mathrm{C}\right)\end{array}$ & 1.0 & 3.0 & 4.0 & 5.0 & 6.0 & 7.0 & 8.0 & 9.0 \\
\hline 27 & 60.3 & 59.1 & 58.5 & 57.9 & 57.7 & 57.9 & 58.1 & - \\
40 & 60.6 & 59.3 & 58.5 & 57.7 & 57.8 & 57.9 & 58.6 & -- \\
60 & 60.5 & 59.4 & 58.7 & 58.5 & 58.3 & 58.7 & 60 & - \\
80 & 60.6 & 59.8 & 59.3 & 59.3 & 59.6 & 59.9 & 61.1 & 61.8 \\
\hline
\end{tabular}

Density as a function of extrusion temperature and draw ratio is shown in Figures $9-11$. The density goes through a minimum with increasing draw ratio for all three polymers and all draw temperatures except at $60^{\circ} \mathrm{C}$ and $80^{\circ} \mathrm{C}$ for sample $\mathrm{A}$ and $80^{\circ} \mathrm{C}$ for $\mathrm{B}$. A minimum in density is also reported by DeCandia et al. ${ }^{36}$ for cold-drawing of LDPE. The decrease at low draw is attributed to the formation of voids during the transformation from lamellar to fiber structure. However, in solidstate extrusion, the lateral constraints imposed by the capillary wall prevents the formation of voids. ${ }^{8}$ In confirmation, Chuah et a $1^{8}$ observe density minima with draw for solid-state extrusion of HDPE. They explain it by the combination of two opposing processes: the crystalline density decreases while the amorphous density increases with draw. This is in accord with Glenz 35 who discusses the increase in amorphous density from the Peterlin model. With increasing draw, one increases the number of extended tie molecules connecting crystal blocks in microfibrils and interconnecting neighboring microfibrils. Since the 


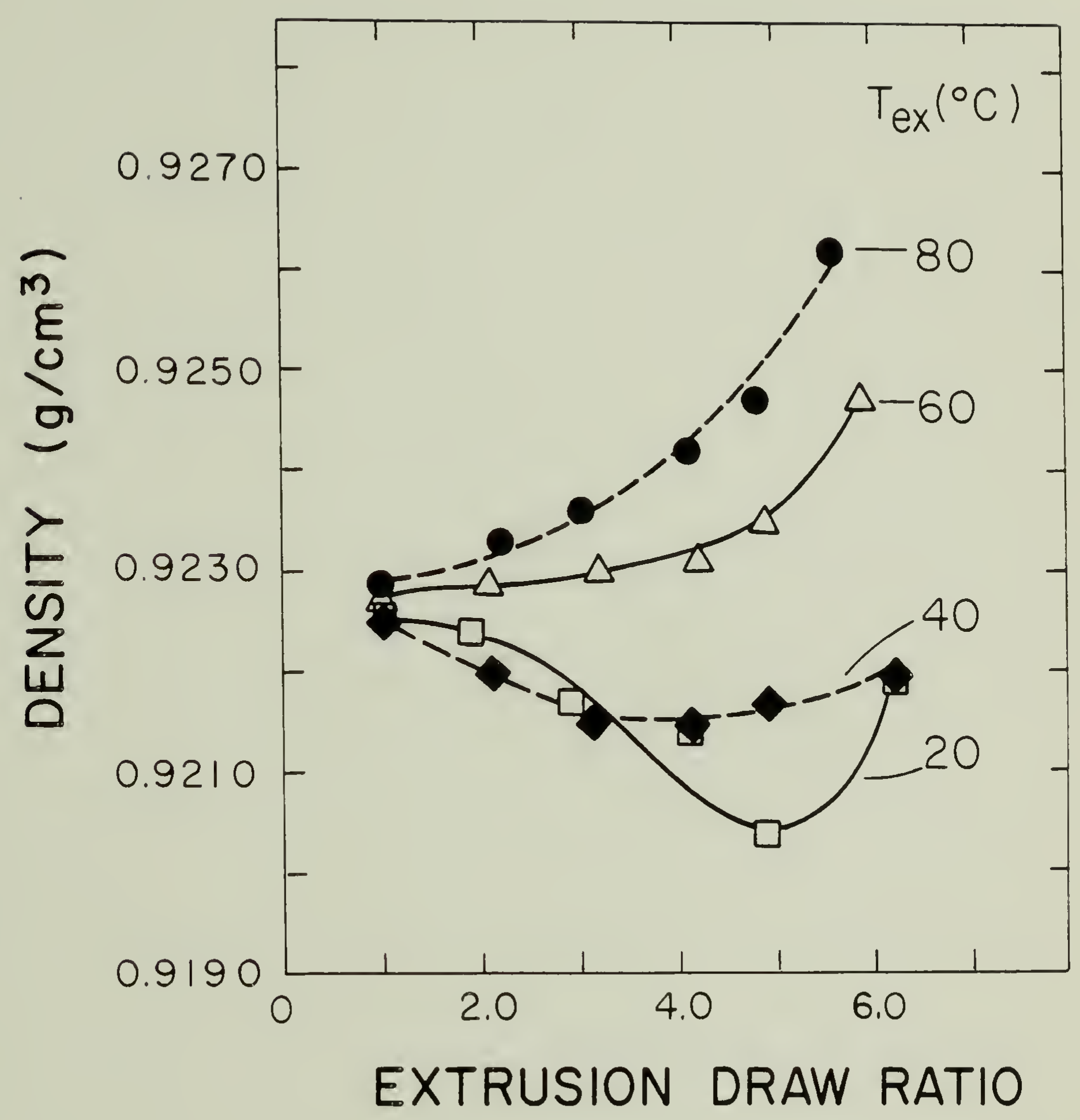

Figure 9. Density of sample A extrudates versus EDR at the extrasion temperatures as shown. 


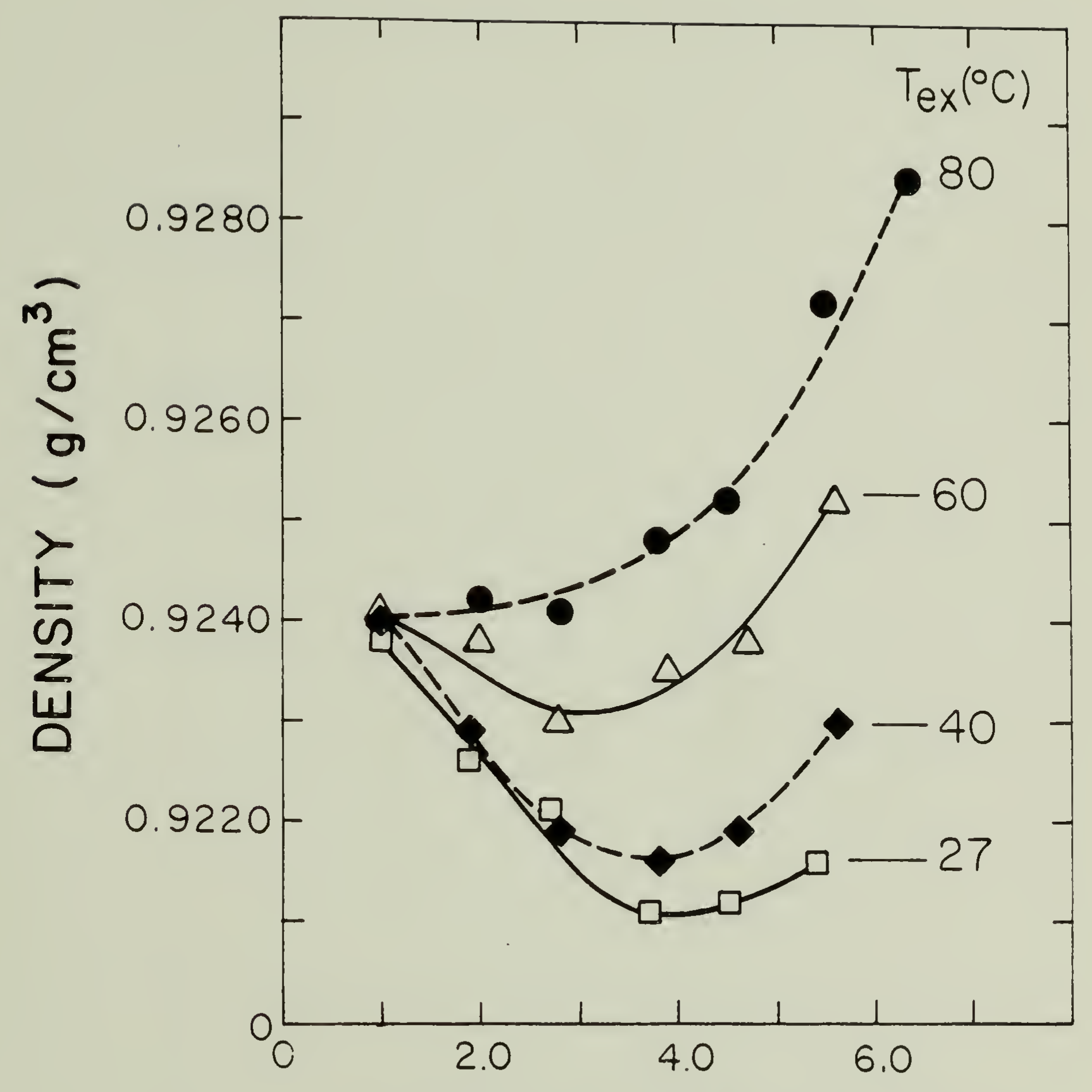

EXTRUSION DRAW RATIO

Figure 10. Density of sample B extrudates versus EDR at the extrusion temperatures as shown. 


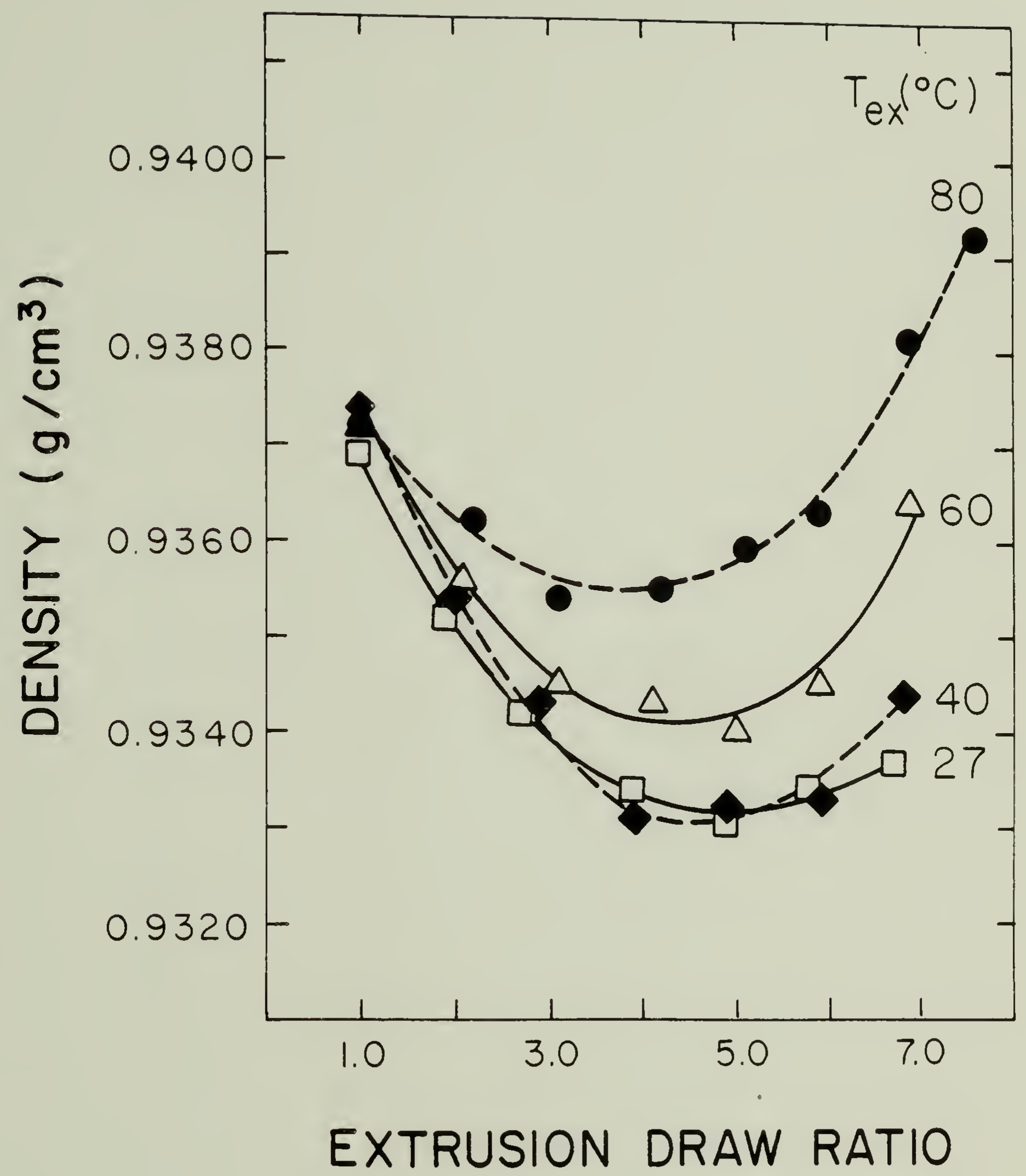

Figure 11. Density of sample C extrudates versus EDR at the extrusion temperatures as shown. 
highly aligned tie molecules should show close packing, their presence increases the amorphous density. Glenz also shows that the density of the crystalline phase decreases on drawing. Therefore at high draw, the amorphous density becomes the determining factor. Hence, the larger the amorphous content, i.e. the lower the degree of crystallinity, the larger the effect on macroscopic density. It is significant that only a slight increase in density from the minimum is observed for HDPE samples of higher amorphous content. 8 For the much larger amorphous component samples used in our study, the increase in amorphous density is substantial enough to give a final density higher than that of the undrawn material (Figures $9-11$ ). Table 22 clearly shows that the increase in density is dependent upon the crystallinity of the andrawn material. It must be pointed out that polymer $B$ has a $\Delta \rho$, i.e.+ 0.0032 , similar to that of $A$ at $E D R=5.5$. 
Table 22

Overall Density Change

\begin{tabular}{ccccc} 
Sample & $\begin{array}{c}\text { Crysta11inity } \\
\text { at EDR }=1.0\end{array}$ & $\mathrm{~T}_{\text {ex }}\left({ }^{\circ} \mathrm{C}\right)$ & $\operatorname{EDR}_{\max }$ & $\Delta \rho\left(\mathrm{g} / \mathrm{cm}^{3}\right) * *$ \\
\hline A & 51 & 80 & 5.6 & +0.0034 \\
B & 52 & 80 & 6.4 & +0.0044 \\
C & 61 & 80 & 7.6 & +0.0019 \\
HDPE 1*** & 74 & 90 & 14 & -0.002 \\
HDPE 2*** & 82 & 100 & 16 & -0.005 \\
\hline
\end{tabular}

*From Equation 10.

$* * \Delta \rho=\rho\left(E_{\max }\right)-\rho(E D R=1.0)$.

**\#HDE samples showing a minimum in density with draw. Data from ref. 8.

It can be seen from Figures $9-11$ that the EDR of minimum density shifts downward when the temperature of extrusion is increased. Eventually, no decrease in density occurs at all as in the case of samples $\mathrm{A}, 60^{\circ} \mathrm{C}, 80^{\circ} \mathrm{C}$, and $\mathrm{B}, 80^{\circ} \mathrm{C}$. At high extrusion temperatures, annealing becomes significant especially at the highest draw ratios wherein annealing times are very large, i.e. lowest extrusion speeds. Moreover, at higher temperatures and for the same draw ratio, the tie molecules are expected to be less oriented and thus will contribute less to the increase in density. Therefore, the density of the crystalline phase must be increasing at least partly because of annealing. This is consistent with the steep increase in density at the highest draw 
ratios. It is also consistent with data reported in Table 22 since annealing at $80^{\circ} \mathrm{C}$ is more significant for samples $A$ and $B$ of lower crystallinity, i.e. lower melting point. The temperature at which the density decrease ceases seems related to the temperature of minimum die swe 11 (Chapter III, section 3). Above this temperature, crystals of more perfection may be produced by the combination of annealing and high draw and thus may also contribute to the density increase. In any case, at those high temperatures, the increase in crystallinity must be real.

\subsection{From Heat of Fusion}

Using the same two-phase model as for crystallinity from density, one can calculate the apparent percent crystallinity knowing the heat of fusion, as determined from the area of the fusion curve. The degree of crystallinity in percent is defined as follows: 37

$$
\text { \% Crysta11inity }=\frac{\Delta H}{\Delta H_{u}}
$$

where $\Delta H$ is the heat of fusion of the partially crystalline specimen and $\Delta H_{u}$ the heat of fusion of the perfect crystal.

The values in Tables 23 - 25 are computed using a value of 69.2 cal/g 10,15 for $\Delta H_{u}$. There are no appreciable changes in crystallinity with neither draw ratio or extrusion temperature for al1 three polymers except for polymer $A$ at $D R=7.0 ; B$ at $D R=7.0,8.0$ and $C$ at $D R=9.0$ at a temperature of extrusion of $80^{\circ} \mathrm{C}$. Despite the large discrepancies, 
i.e. up to $13 \%$, between the values of crystallinity determined from heat of fusion and those from density, the two methods are still comparable to some extent. The increase in crystallinity at high draw and extrusion temperature support the reality of the previous conclusion (Chapter IV, Section 1.1). This increase is due only in part to annealing since at $\mathrm{T}_{\text {ex }}=80^{\circ} \mathrm{C}$ the crystallinity at $\mathrm{DR}=8.0$ is lower than that at $D R=9.0$ whereas annealing time is higher for the former. Therefore, it is probably the combined effects of annealing and draw that cause the increase in crystallinity.

Table 23

Crystallinity (\%) from Heat of Fusion for Sample A

\begin{tabular}{lcccccc}
$\begin{array}{c}T_{(e x} \\
(0)\end{array}$ & 1.0 & 3.0 & 4.0 & 5.0 & 6.0 & 7.0 \\
\hline 40 & $37.6 \pm 0.5$ & $38.7 \pm 0.5$ & $39.0 \pm 0.6$ & $39.7 \pm 0.5$ & $40.3 \pm 0.2$ & $40.4 \pm 0.3$ \\
60 & $37.6 \pm 0.9$ & $40.7 \pm 0.2$ & $40.5 \pm 0.2$ & $41.1 \pm 0.4$ & $41.2 \pm 0.9$ & $42.8 \pm 0.5$ \\
80 & $38 \pm 1$ & $41 \pm 1$ & $41.7 \pm 0.2$ & $42.7 \pm 0.2$ & $42.1 \pm 0.3$ & $44.2 \pm 0.2$
\end{tabular}




\section{Table 24}

Crystallinity (\%) from Heat of Fusion for Sample B

\begin{tabular}{|c|c|c|c|c|c|c|c|}
\hline${ }^{T}\left(\delta \frac{x}{C}\right)$ & 1.0 & 3.0 & 4.0 & $\begin{array}{c}\text { Draw Ratio } \\
5.0\end{array}$ & 6.0 & 7.0 & 8.0 \\
\hline 27 & $39 \pm 0.6$ & $39.9 \pm 0.6$ & $40.6 \pm 0.3$ & $40.9 \pm 0.3$ & $40.8 \pm 0.1$ & $41.6 \pm 0.7$ & - \\
\hline 40 & $40 \pm 1$ & $40.1 \pm 0.3$ & $41.0 \pm 0.1$ & $40.6 \pm 0.1$ & $41.0 \pm 0.2$ & $41.0 \pm 0.4$ & -- \\
\hline 60 & $37.9 \pm 0.6$ & $41 \pm 1$ & $40.4 \pm 0.3$ & $40.2 \pm 0.5$ & $40.4 \pm 0.5$ & $42.3 \pm 0.8$ & - \\
\hline 80 & $38.3 \pm 0.6$ & $41.4 \pm 0.4$ & $41.1 \pm 0.4$ & $41.8 \pm 0.9$ & $42.1 \pm 0.5$ & $44.0 \pm 0.6$ & $45.3 \pm 0.3$ \\
\hline
\end{tabular}

Both the calorimetric and density calculations for crystallinity depend upon the assumption of an ideal two phase mode1. Therefore, if the two methods are used for estimating the crystalline/amorphous ratio, it is to be expected that they may give numerically different results. 33,37 Indeed, such discrepancies are reported for solid-state extruded $\mathrm{HDPE}^{8,15}$ and they run as high as $7 \%$ crystallinity. ${ }^{8}$ However, those observed for our samples are as high as $13 \%$ (Table 26), probably beyond any inherent discrepancies. 


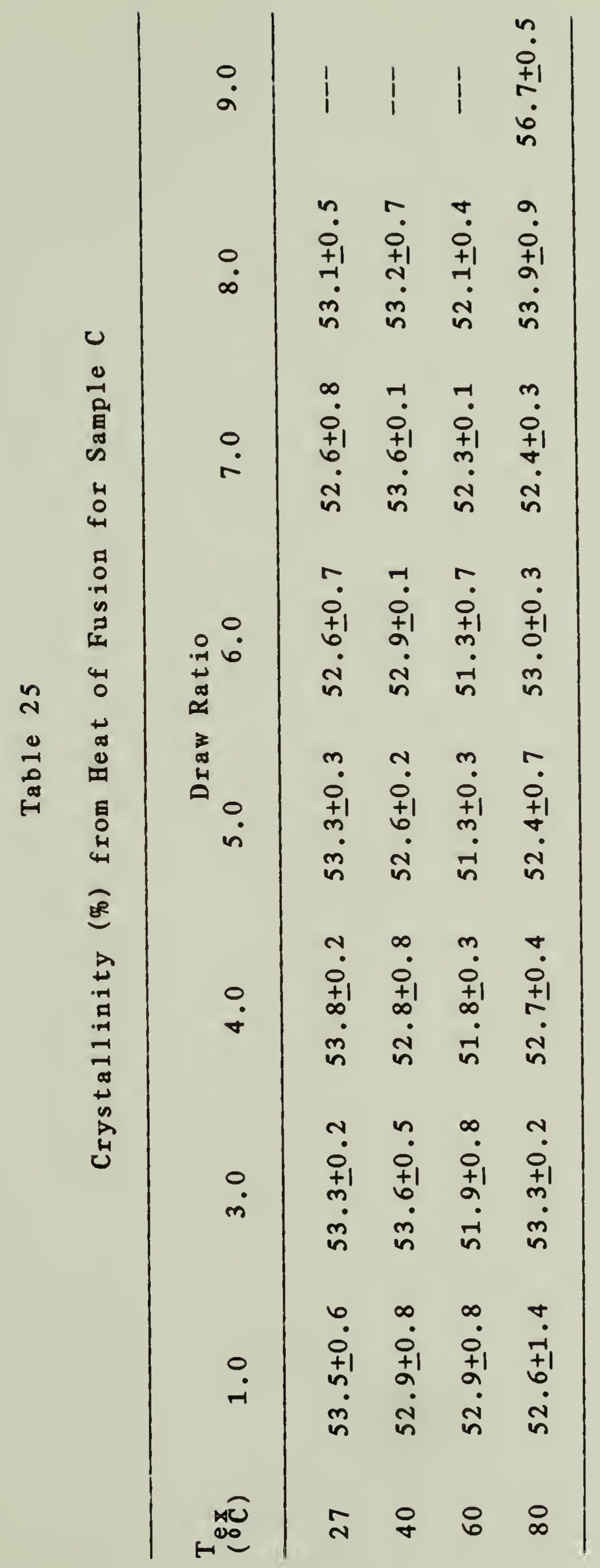


Table 26

Difference Between Crystallinities from Density and Heat of Fusion

\begin{tabular}{lcccc}
\hline Sample & $\mathrm{T}_{\mathrm{ex}}\left({ }^{\circ} \mathrm{C}\right)$ & $\mathrm{DR}_{\max }$ & $\begin{array}{c}\text { Difference }(\%) \\
\text { at } \mathrm{DR}=1.0\end{array}$ & $\begin{array}{r}\text { Difference }(\%) \\
\text { at } \mathrm{DR}_{\max }\end{array}$ \\
\hline $\mathrm{A}$ & 80 & 7.0 & $\sim 13$ & $\sim 9$ \\
$\mathrm{~B}$ & 80 & 8.0 & $12-13$ & $\sim 9$ \\
$\mathrm{C}$ & 80 & 9.0 & $7-8$ & $\sim 5$ \\
\hline
\end{tabular}

Draw could be causing crystallinity differences in two ways. First, the amorphous density may change significantly with draw and thus the calculated apparent crystallinity from density may be too high. Second, since shrinkage is an exothermic process, 38 the energy released upon relaxing the taut tie molecules during melting may lower the endothermic heat of fusion. However, as seen in Table 26, discrepancies are higher for the undrawn material. Also, they are larger for the lower crystalline content materials, i.e. A and B. Another reason could be that during the melt scan, some recrystallization going along with fusion may yield an apparent low heat of fusion. Samples of polymer A extruded at $D R=6.0$ and $T_{e x}=40^{\circ} \mathrm{C}$ were scanned at different heating rates: 10,40 and $80^{\circ} \mathrm{C} / \mathrm{min}$. The resulting crystallinities were 40,39 and $37 \%$. These results militate against recrystallization being a cause to the discrepancies observed because there is less time for recrystallization to take place at high heating rates. Therefore, it must be that the value $69.2 \mathrm{cal} / \mathrm{g}$ used as $\Delta \mathrm{H}_{\mathrm{u}}$ the heat of fusion for the perfect crystal is too high for LDPE. 


\section{Me1ting Temperatures}

\subsection{Me1ting point}

The melting point defined by the peak value of the fusion curve for a structure having a graded degree of crystal perfection more nearly approximates the temperature at which the majority of the crystallites melt rather than the temperature at which all crystallinity disappears. 9,37 Figure 12 intercompares this melting point as a function of extrusion draw ratio for the three polymers extruded at $80^{\circ} \mathrm{C}$. The melting point for samples $A$ and $C$ drops at EDR $>2.0$ and then remains constant. For B, MP decreases regularly with draw. There is, though, little temperature dependence of MP.

The melting of low density polyethylenes as a function of draw differs markedly from that of HDPE for which the melting point is reported to increase modestly with draw.9-11,39-41 For both classes of PE, the melting point is insensitive to extrusion temperature, ${ }^{6}$ except perhaps at draw ratios above 15.41 The melting behavior of our polymers, except possibly for B, is not anomalous: Buckley and Long ${ }^{2}$ a 1 so observed no appreciable change in the melting points for LDPE. Hope.et a 1.40 report a copolymer behavior different from that of the other 1 inear homopolymers. The former shows no increase in MP below DR $=15$. This suggests that the difference stems from the difference in short chain branching and thus in crystallinity. However, in many instances, 10 the range of draw ratios investigated wherein MP shows an increase does not include low draw ratios, i.e. $<10$. 


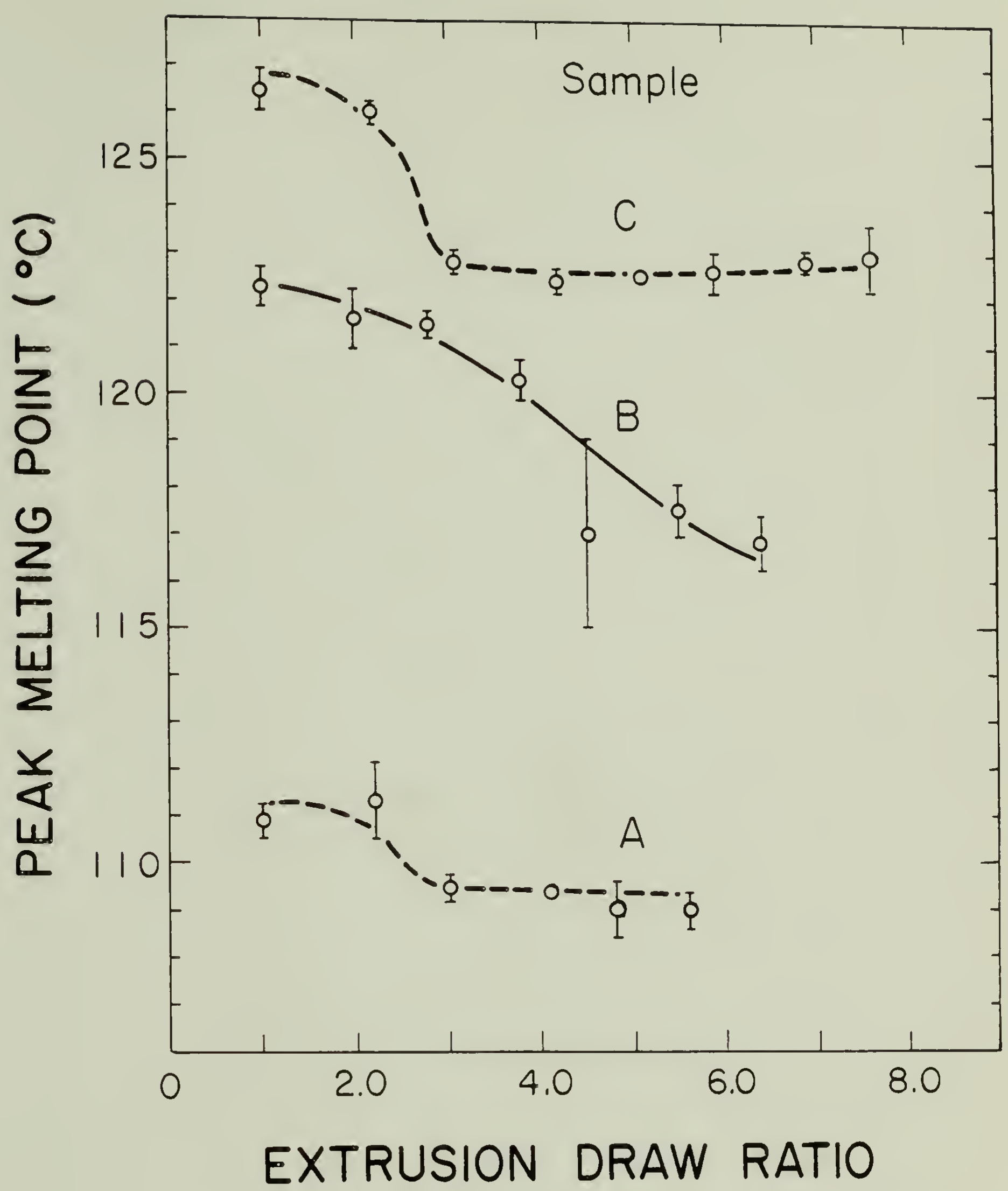

Figure 12. Peak melting point versus EDR for samples $A, B$ and C extruded at $80^{\circ} \mathrm{C}$. 
It is expected that larger and more regular crystallites give a higher MP. 37 Consequently, some authors 10,39 think that the increase in melting point with DR is connected with increased perfection and homogeneity. Another explanation is based on a highly constrained fibrillar morphology. ${ }^{12}$ Configurational constraints in the early stages of the melting process lead to small entropy variations between the solid and molten state. This gives rise to an "apparent" melting point higher than the equilibrium thermodynamic melting temperature of crystals. Therefore, the increase of MP with DR can be explained by the fact that the entropy constraint in the non-crystalline regions increases during drawing. ${ }^{41}$ This is also referred to as superheating by others 1 ike Wunderlich. 38

If an increase in MP were due to an increase in crystal perfection, it would be reasonable to think that a constant or decreasing MP mean respectively no significant change and a decrease in crystal perfection. In this perspective, the initial drop in MP may be viewed as the result of the destruction of the original lamellar structure but taking longer in. the case of polymer B. Concerning the initial drop, it must be noted that even when the melting points increase with DR, they are not necessarily higher than that of the original isotropic PE provided that the latter is crystallized at low supercooling rather than rapidy quenched from the melt to room temperature. ${ }^{40}$ On the other hand, if the second explanation is retained, no change in MP with DR means that there is no significant change in amorphous constraint or else that calorimetry is not a method sensitive enough to measure the differences 
in oriented strand morphology. 12

Just as HDPE, $9,12,41,42$ our polymers seem also to superheat.

Polymer A extruded at $D R=6.0$ and $T=40^{\circ} \mathrm{C}$ is shown as an example:

$$
\text { Scanning Rate }\left({ }^{\circ} \mathrm{C} / \mathrm{min}\right) \quad M P\left({ }^{\circ} \mathrm{C}\right)
$$

These values have not been corrected for the instrument lag. Yet, they are still lower than those reported by Mead ${ }^{42}$ for $\mathrm{BDPE}, \mathrm{i} . \mathrm{e}, \sim 20^{\circ} \mathrm{C}$ increase in MP going from 10 to $80^{\circ} \mathrm{C} / \mathrm{min}$. This may mean that superheating effects of LDPE are small compared to those of HDPE. In other words, the change in amorphous constraint may not be large enough for LDPE to induce an increase of the melting point large enough to be recorded. In any case, in trying to understand the morphology through the thermal properties, caution is recommended. As clements et a1. 41 show, the extent of superheating depends markedly upon draw ratio and molecular weight and MP is strongly dependent on heating rate over a wide region. This clearly militates against attaching any physical significance to results obtained at a specific heating rate.

\subsection{Multiple me1ting peaks}

Double melting peaks are a notable characteristic of the fusion curves (Figures 13 - 15) especially for polymer B. However, their appearance is not reproducible, appearing only occasionally on me 1 ting 


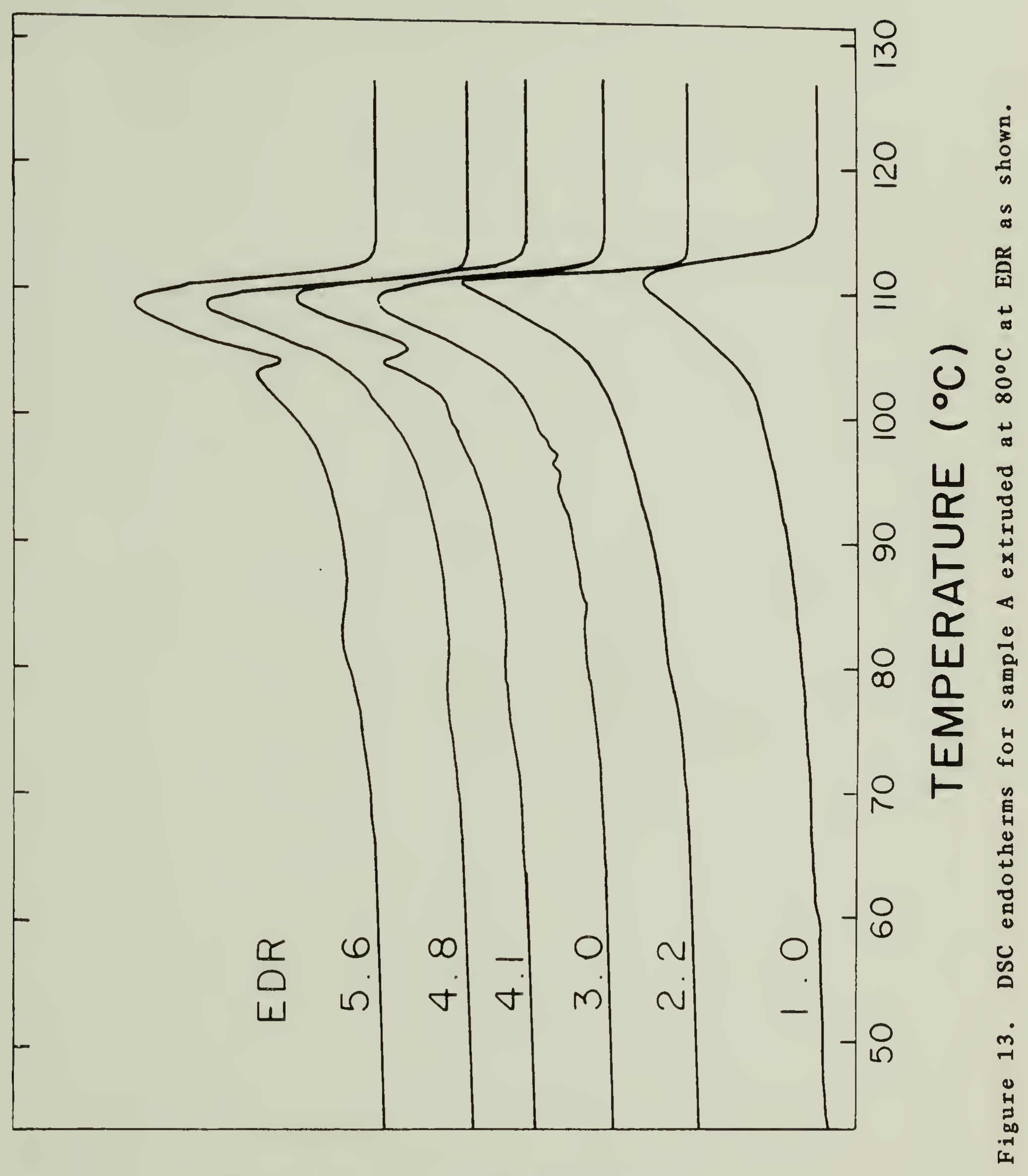

WY $\exists$ HLON $\exists$ 


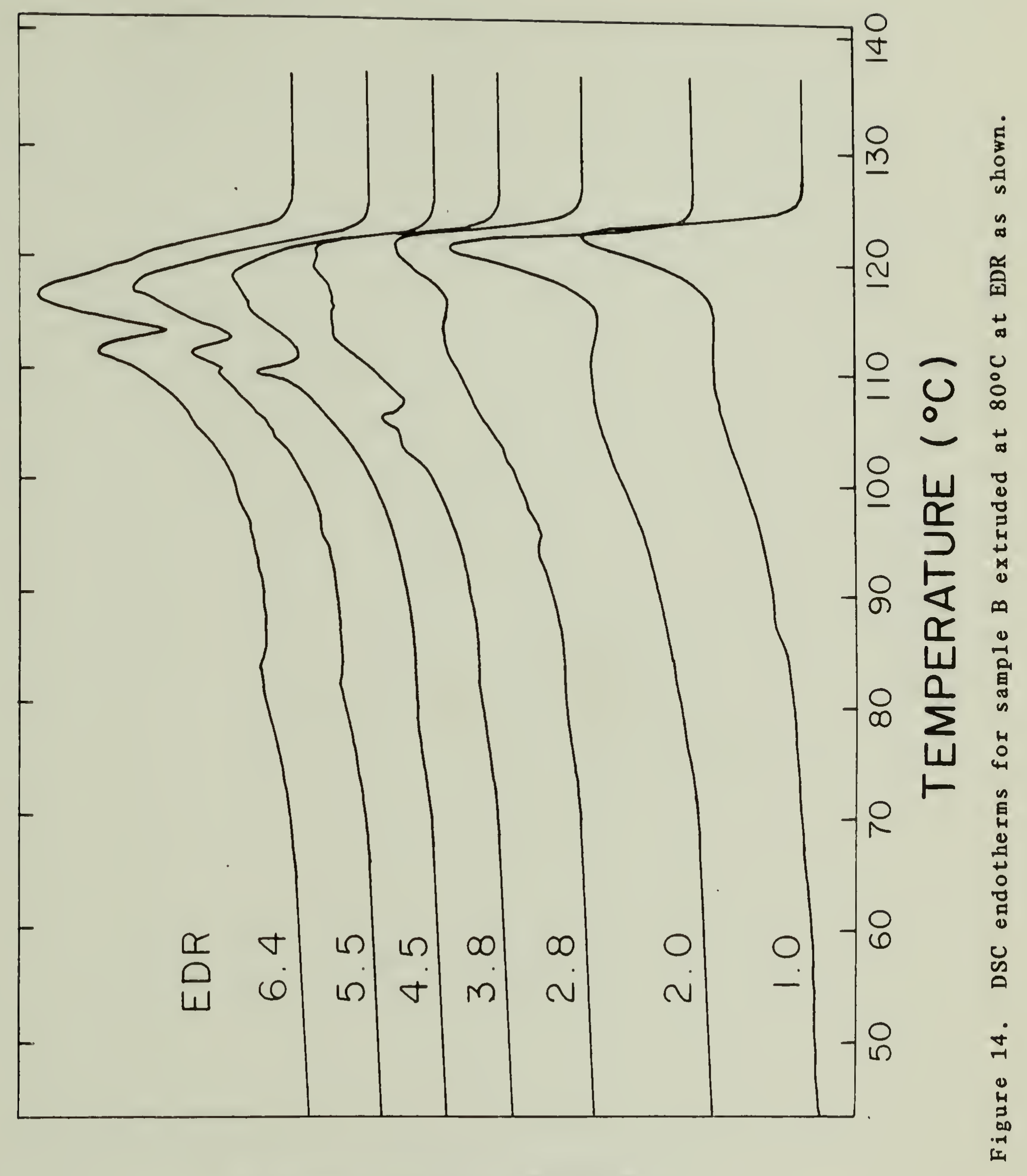

WY $\exists$ HOON 


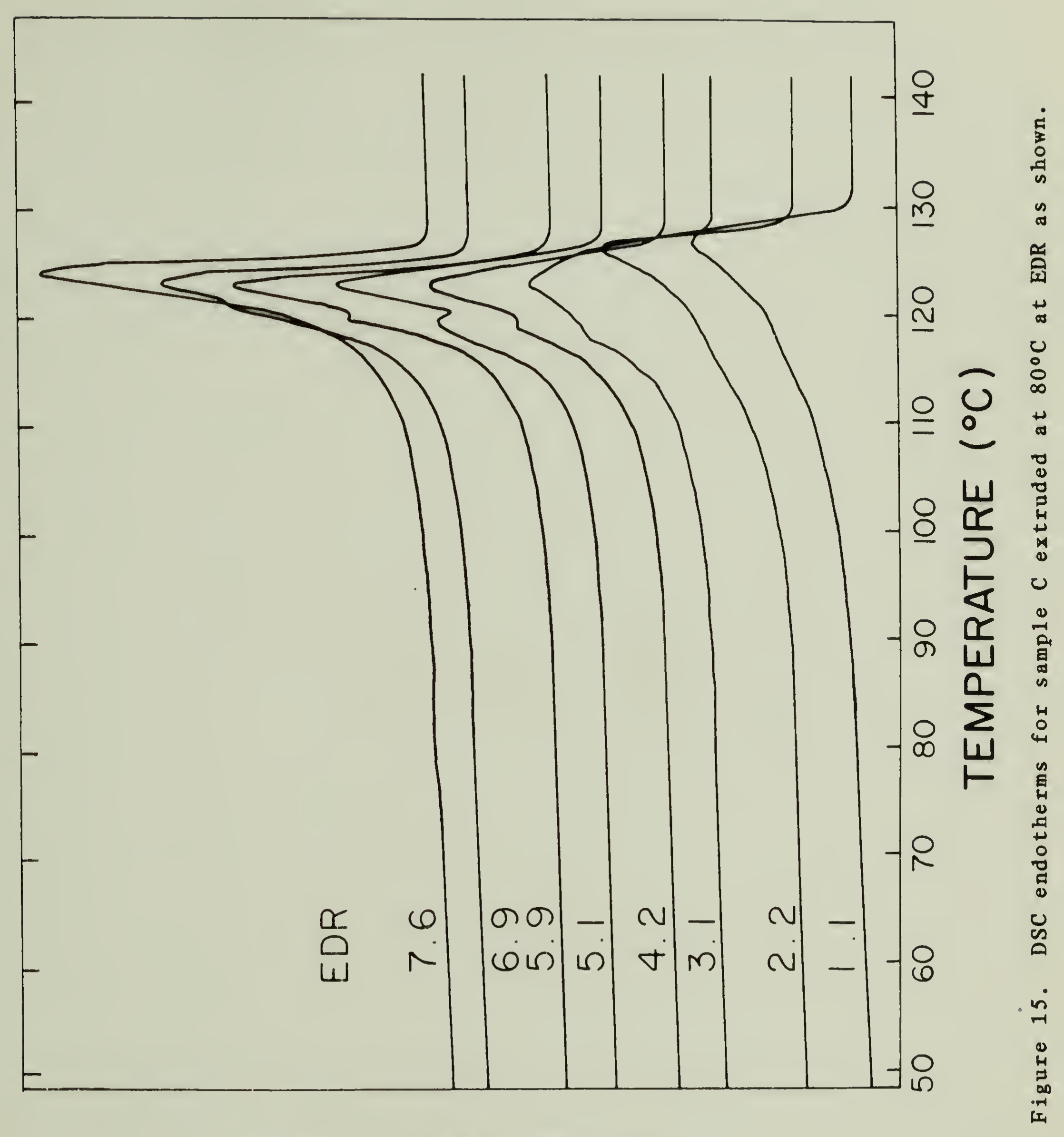

WY $\exists \mathrm{H} \perp O O N \exists$ 
polymer C, for which the most conspicuous feature is the increasing sharpness and smoothness of the melting peak at higher draw ratios. Multiplo melting peaks for drawn linear PE $13,14,39$ and othor polymers 43,44 have been reported. Aharoni and Sibilia ${ }^{39}$ correlate the appearance of throe melting peaks to the oxistence of threo morphologios in the extrudates. Southern ${ }^{13}$ and Moad ${ }^{14}$ with coworkers associate the dual peaks observed with chain-folded and chain extendod crystals. Be $11^{43}$ suggests that one endotherm is caused by melting of chain-folded crystals while the other is due to molting of less porfect bundle crystals. Pope 45 thinks that doublo molting bohavior of oriontod LDPE is an offect inherent to DSC measurement: the main endotherm is a result of roorganization during hoating in DSC while the small endotherm represonts material that is unable to recrystallize into the form of large lamellae with increased molting points. Recrystallization during the DSC scan is also supported by Swoot. 44

Annealing can also produco multiple molting poaks. 45,46 Indoed, Figures 13 and 14 show small bumps around $80^{\circ} \mathrm{C}$, charactoristic of annoaling at $80^{\circ} \mathrm{C}$ in the capillary zone. They are prominont at highest draw ratios, i.e. for larger annoaling times. Largor annealing timo at fixod annoaling temporaturo - moves the second peak, or sometimos just the shouldor, upward in temporature. ${ }^{45}$ Whon the crystallization prossure is roleased at a temporature betwoon 80 and $90^{\circ} \mathrm{C}$ during the proparation of the original billet, the thermodynamic melting temperature is lowered. Annealing can thus take place yiolding a prominent shoulder in the fusion curve of the undrawn material. Since 
polymer B has a lower melting point than $C$, it is expected to be affected by annealing more significantly and hence shows more remarkable shoulders as seen in Figures 14 and 15.

Despite inconsistencies, there are trends: irregularities in the endotherms start showing ap at EDR 3.0. Endotherms become smoother and sharper at high draw whether they are single or split into two peaks. Also, irregularities and peak splitting are most pronounced in polymer B. It may be reasonable then, to think that differences in crystal size and perfection already present in the original PE are enhanced by drawing, especially during the transformation from the lamellar to the microfibrillar stracture. The fact that sample c peaks become sharper at $D R=9.0$ may mean increased homogeneity. Therefore this may suggest that all the structure has become microfibrillar at DR $=9.0$ for $C$ but has not achieved complete transformation for the two other polymers even at their highest DR. Note, however, that Hunder 1 ich 38 points out that mach of the narrowing of the melting peak is not necessarily due to a narrower crystal size but results from the relaxation of the sample during partial melting and reorganization:

\section{Tensile Modulus}

As shown in Figures 16-18, the tensile modnlus E varies similarly with EDR for all three low density polyethylenes. After going through a minimum at near $E D R=2$, the modulus increases drastically with draw. The overall increase is up to $4.5,2.5$ and 4.0 times that of the original isotropic polymers for A, B and C respectively. There is also 


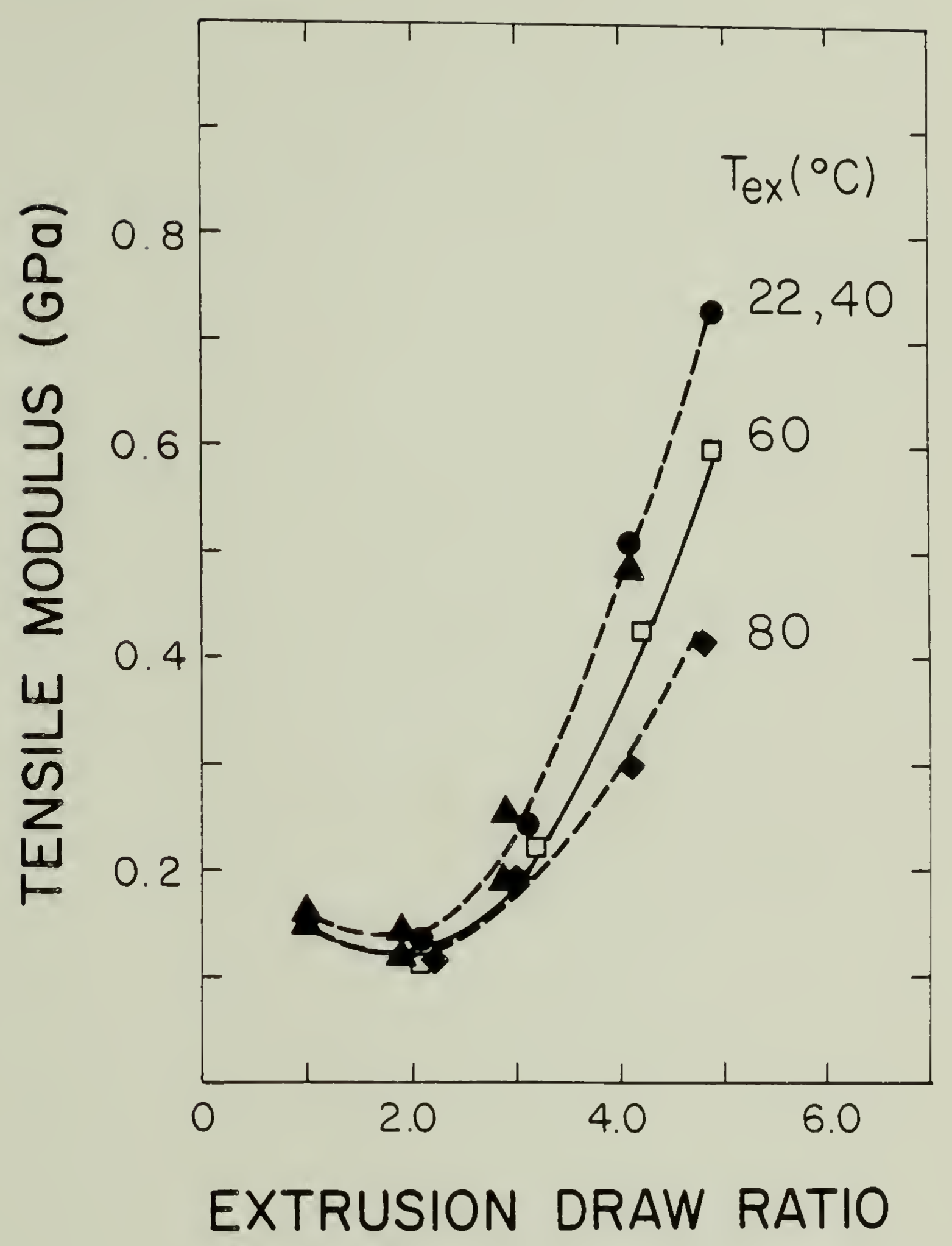

Figure 16. Tensile modulus versus EDR for sample $A$. $T_{\text {ex }}=27$ $(\Lambda) ; 40(\bullet) ; 60(\square) ; 80^{\circ} \mathrm{C}(\bullet)$. 


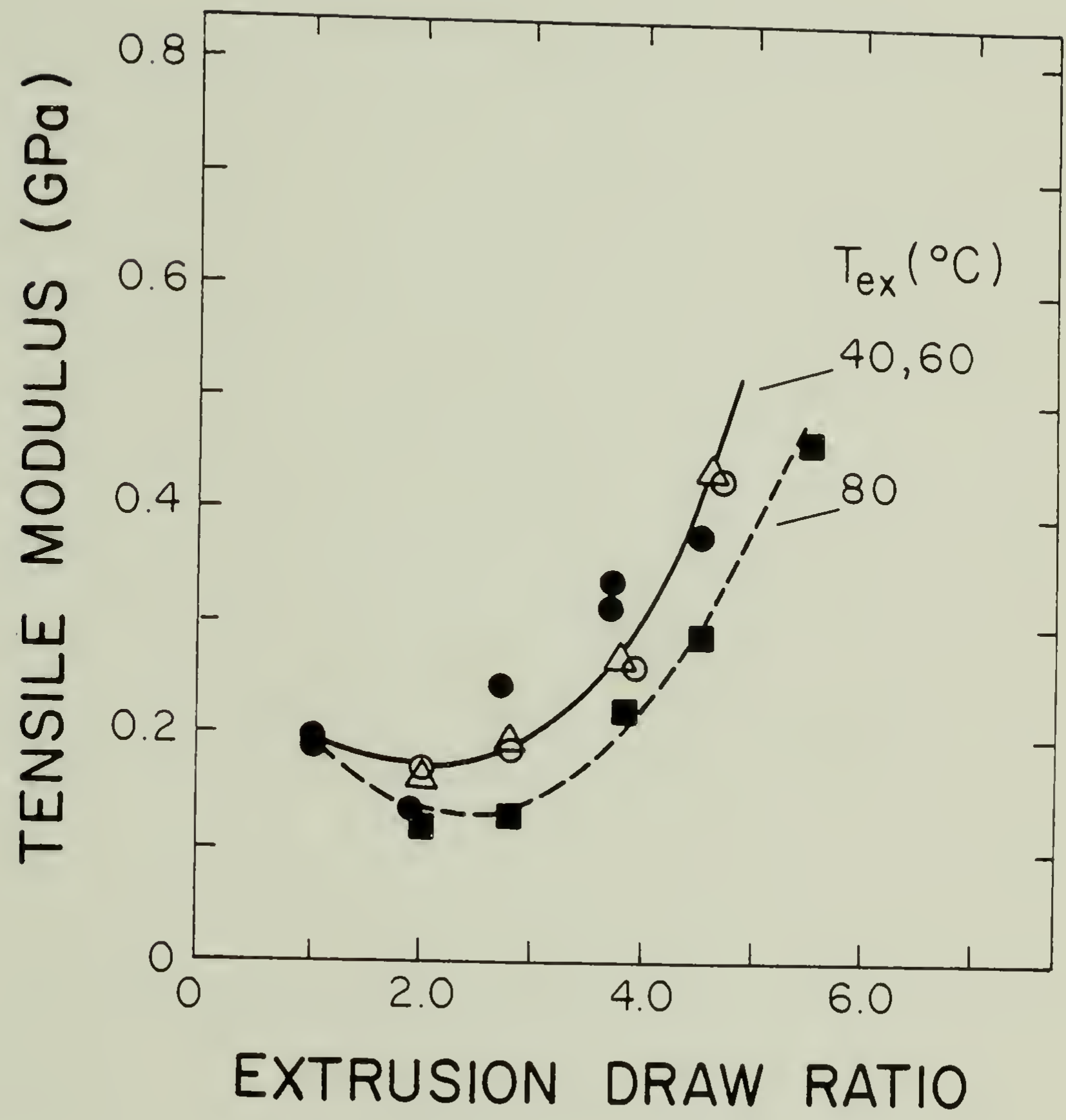

Figure 17. Tensile modulus versus EDR for sample $B$. $T_{e x}=$ $27^{\circ} \mathrm{C}(0) ; 40^{\circ} \mathrm{C}(\Delta) ; 60^{\circ} \mathrm{C}(0) ; 80^{\circ} \mathrm{C}(\mathrm{a})$. 


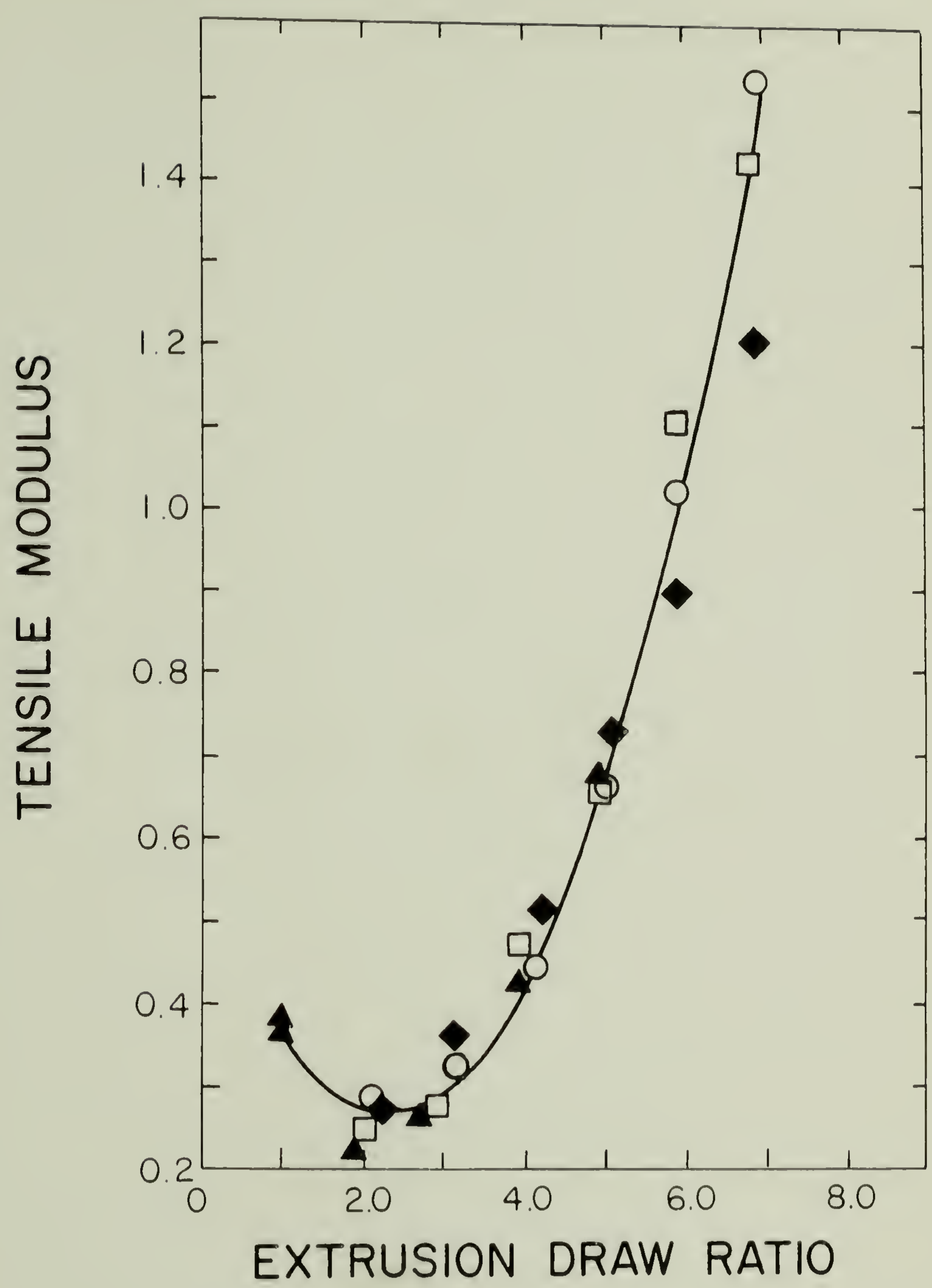

Figure 18. Tensile modulus versus EDR for sample C. $T_{\text {ex }}=27$ (4); $40(\square) ; 60(0) ; 80(\bullet)$. 
a minor but clear dependence of modulus on extrusion temperature. At higher draw ratios and for the lower crystallinity polymers, A and $B, E$ decreases with increasing extrusion temperature. Polymer A shows the most rapid increase in modulus with draw. Although undrawn A has a lower modulus, it reaches a higher value than its linear counterpart $B$. That C reaches higher values than the former stems more from its higher drawability at these conditions than from its higher crystallinity.

The effect of draw on tensile modulus for LDPE differs from that for HDPE. 11 In the latter case, the modulus increases slowly with draw at draw ratios less than 10-15 whereas at higher draw ratios, the modulus increases rapidly and linearly with draw. Also, the minimum in modulus at low EDR is not observed in accord with Buckley and Long ${ }^{2}$ who found only a slight increase in tensile modulus on solid state extrusion of LDPE. Our results compare we11 with those for cold-drawn LDPE 23,47 including the anomalous pattern of the minimum modulus which seems to be unique to low density polyethylene. ${ }^{48}$ The mechanical anisotropy of LDPE has been studied extensively by Ward and his co-workers. ${ }^{46-53}$ The highest moduli attained are shown in Table 27 which also includes the highest moduli reported in literature for LDPE. EDR max refers to the highest EDR at which a "Good" (see Tables 6 - 8) was obtained.

DeCandia et a1.21 attribute the higher modulus of LLDPE compared to that of LDPE (see Table 27) to the higher draw ratio obtainable in the former, which in turn is a consequence of the shortness of the branches. This observation is opposite to ours. The difference of molecular weight may not be the reason, since Young's modulus for HDPE is 
essentially independent of molecular weight. ${ }^{7}$ The difference may be related to the more rapid strain hardening observed in polymer A during the extrusion process (see Chapter III, Section 1). This is similar to the more rapid increase in modulus for $A$ with respect to B. If strainhardening is an indication of the change in polymer structure from lamellar to fibrillar, a more rapid strain-hardening will mean then more taut tie molecules or continuous crystals at the same draw ratio. Consequent1y, if the tensile modulus is determined by the fraction of taut tie molecules, 23 it will be higher for A than for B at the same draw ratio.

Table 27

Presently Achievable Tensile Moduli of Polyethylene

Sample Density $\left(\mathrm{g} / \mathrm{cm}^{3}\right) \quad \operatorname{EDR}_{\max } \quad \mathrm{E}(\mathrm{GPa}) \quad$ Reference

$\begin{array}{lcccc}\text { A } & 0.920 & 4.9 & 0.73 & - \\ \text { B } & 0.920 & 5.5 & 0.46 & - \\ \text { C } & 0.935 & 6.9 & 1.5 & \text { Hadley et a } 1 .{ }^{49} \\ \text { LDPE* } & -- & 6.0 & 0.83 & \text { DeCandia et a1. } \\ \text { LDPE* } & 0.915 & 6.0 & <0.75 & \text { DeCandia et a1. } \\ \text { LLDPE* } & 0.914 & 8.0 & 1.1 & \text { Zachariades et a } 1 .{ }^{11} \\ \text { HDPE** } & -- & 40 & 70 & \end{array}$

* Cold drawn.

**Solid state extruded.

According to DeCandia et a $1 .,{ }^{23}$ the development of voids between lamellae oriented perpendicular to the draw direction explains the 
minimum in both the density and the elastic modulus with draw ratio. This effect disappears as a consequence of the formation of fibrous material with substantially higher axial elastic modulus. It can be seen from Figures 9 and 10 that the density of polymers $A$ and $B$ extruded at high temperatures does not go through a minimum with draw ratio, whereas modulus does. Furthermore, in solid state extrusion, the lateral constaints imposed by the capillary may prevent voidings. A preferred explanation for the minimum has been given by Frank et a1. 50 on the basis of two mechanisms: c-shear process and twin boundary migration. The c-axis shear mechanism is related to the mobility of the structure arising from an appreciable branch content which also gives rise at room temperature to a low shear modulus on planes along and perpendicular to the draw direction. 51 This is confirmed by using a testing temperature of $-125^{\circ} \mathrm{C}$ at which the drop in modulus at low draw ratios is not observed. Indeed, mobility and the effects of mechanical twinning are suppressed at low temperatures.

Using orientation functions from NMR, Ward 53 showed that the mechanical anisotropy of LDPE is we 11 predicted by the aggregate model. In this model, the unoriented fibre or polymer can be regarded as an aggregate of anisotropic elastic units whose elastic properties are those of the highly oriented fiber or polymer. 47,52 This model does not take into account any change in morphology. This leads them to conclude that the mechanical anisotropy of cold-drawn LDPE relates to the orientation of the crystalline region. $47,48,51,53$ This differs from the Peterlin model which presupposes a morphological change: i.e. that the 
fraction of the taut tie molecules in the amorphous layers contributes and practically determines the axial modulus.

\section{Orientation}

\subsection{Birefringence}

Birefringence has been chosen to assess the extent of orientation during solid state extrusion of low density polyethylenes because it may be directly related to the permanent strain. 47 It is also a relatively simple technique. Birefringence is the difference between refractive indices along and perpendicular the draw direction. As the chain becomes more oriented, birefringence $\Delta n$ increases as defined by the following equation: 47

$$
\Delta \mathrm{n}=\Delta \mathrm{n}_{\max }\left(1-\frac{3}{2} \overline{\sin ^{2} \theta}\right)
$$

where $\Delta n_{\max }$ is the maximum birefringence of full orientation and $\theta$ the angle between the chain axis and the draw direction. According to equation $12, \Delta \mathrm{n}$ initially rises sharply with increasing draw ratio and then turns over to a plateau at high draw. ${ }^{53}$ This is indeed what we observe for our low density polyethylenes in Figure 19. (Figure 19 has been drawn using uncertainty bars which have been deleted from the figure to allow for clarity.)

From Figure 19, we can see that within precision, $A$ and $B$ are undistinguishible, whereas $C$ of higher crystallinity reaches higher values of birefringence: $0.068 \pm 0.009$. This value is comparable with 


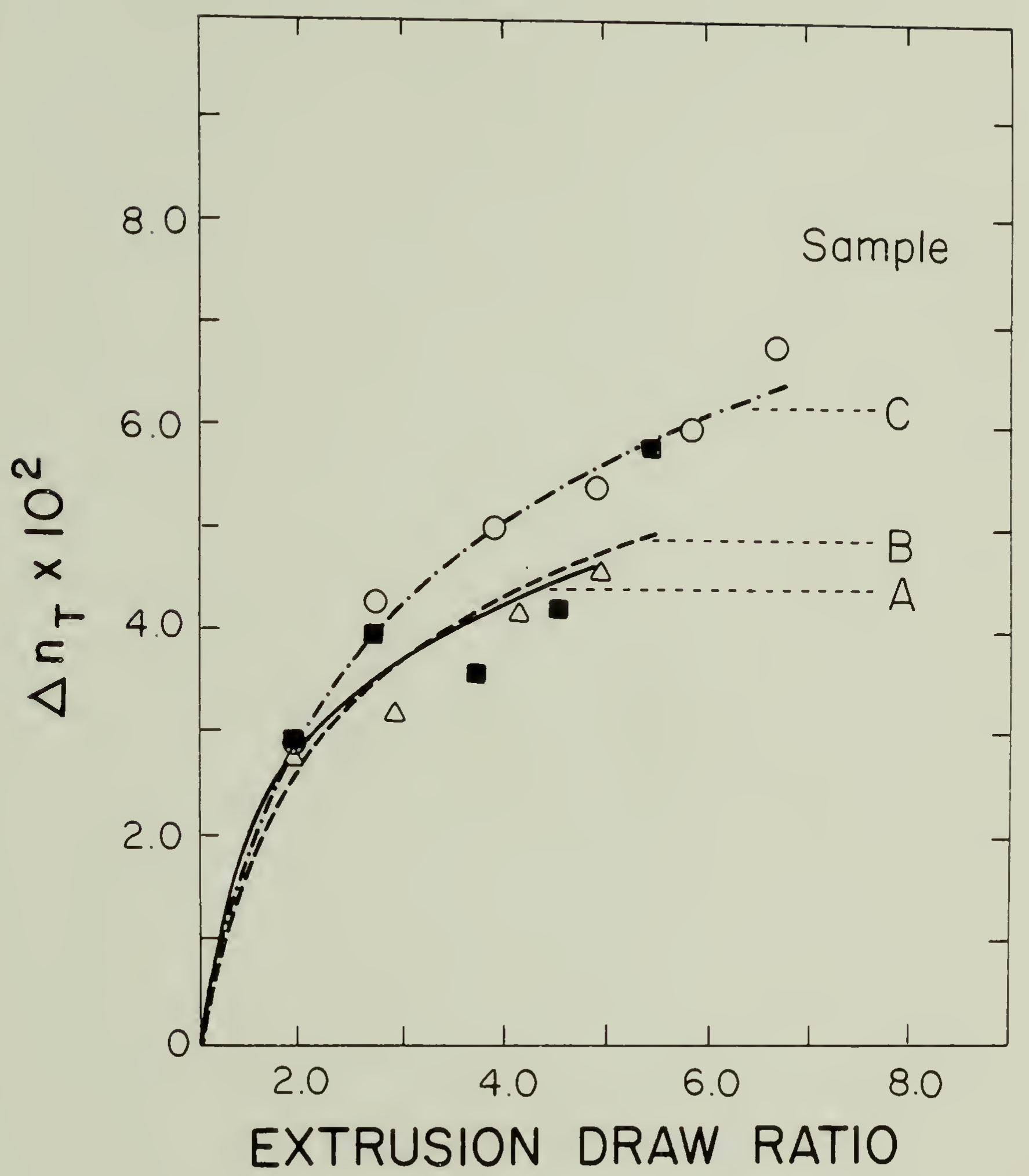

Figure 19. Total birefringence versus EDR for samples $A(\Delta)$;

$B(0)$ and $C(0)$ extruded at room temperature. 
those obtained for ultradrawn HDPE fibers: ${ }^{11} 0.062 \pm 0.002$. The highest value in birefringence for polymer $A$ is $0.046 \pm 0.004$ at $E D R=$ 4.9 and extrusion temperature $\mathrm{T}_{\mathrm{ex}}=22^{\circ} \mathrm{C}$ which is comparable to that of cold drawn LDPE. $52,54,55$ A1so, both extruded and cold-drawn LDPE show the same pattern in birefringence change with draw. Therefore, it seems that birefringence is not influenced by long branching, at least not within the precision of our results. The small but clear extrusion temperature dependence of birefringence is noticeable in the case of polymer A as shown in Figure 20 but not in that of B or C perhaps because of the large uncertainty. The higher birefringence at lower draw temperature may be explained in terms of higher draw efficiency The lower the temperature of draw and the higher the fraction of energy input that is stored elastically and used to reduce the conformational entropy by drawing of polymer chains. ${ }^{26}$ In other words, there is less viscous dissipation at lower temperature. This is consistent with the observation that the modulus of samples extruded at lower temperature is higher (see Chapter IV, Section 3). However, it is not consistent with the observation that the crystal orientation produced at a given elongation is greater for stretching at a higher temperature than a lower. 56 According to Stein, 56 this is due to the fact that the intercrystalline "interference" which reduces the ability of the crystals to orient is less at higher temperatures. The difference in the method of deformation may be causing the contradictory observation. The reason may be that viscous flow is more significant in the extrusion process especially at high temperatures. 


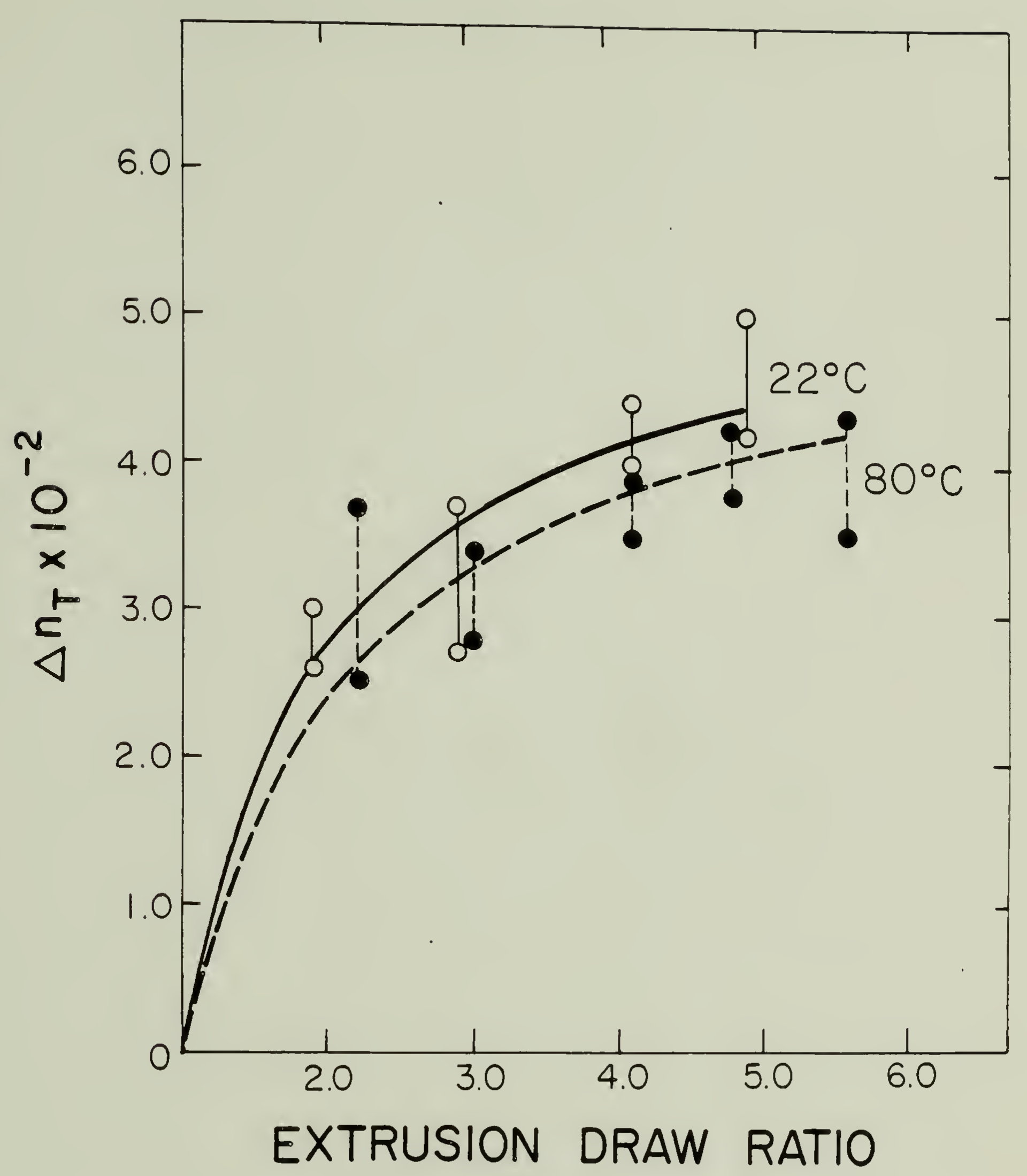

Figure 20. Total birefringence versus EDR for sample A extruded at 22 and $80^{\circ} \mathrm{C}$. 
Total birefringence is the sum of different contributions:

orientational, form and deformation birefringence. It can therefore be expressed as: ${ }^{17}$

$$
\Delta \mathrm{n}_{\mathrm{T}}=\Delta \mathrm{n}_{\text {or }}+\Delta \mathrm{n}_{\text {form }}+\Delta \mathrm{n}_{\text {def }}
$$

Form birefringence, $\Delta n_{\text {form, }}$ originates from having a region of anisotropic shape of particular refractive index imbedded in a second region of different refractive index, ${ }^{56}$ crystalline and amorphous regions in the case polyethylene. For cold-drawn LDPE, it is found 56 to reach a maximum value of $\sim 0.003$ which is of the same order as the uncertainty in our measurements: $\Delta n_{\text {form }}$ is thus neglected. The deformation birefringence $\Delta \mathrm{n}_{\mathrm{def}}$, also called the distortion birefringence, 26 arises as a result of localized polarizibility changes caused by bond angle distortion or "stretching" of chemical bonds. $\Delta n_{\text {def. }}$ is usually sma 11 and also consequently neglected. ${ }^{26}$ Thus, we are left with the orientational birefringence only. The latter results from the preferential alignment of the polymer chains on drawing and is the sum of two contributions: those of the crystalline and amorphous phases. $\Delta n_{T}$ can therefore be expressed as: ${ }^{26}$

$$
\Delta \mathrm{n}_{\mathrm{T}}=\mathrm{X} \Delta \mathrm{n}_{\mathrm{c}}^{\mathrm{o}} \mathrm{f}_{\mathrm{c}}+(1-\mathrm{X}) \Delta \mathrm{n}_{\mathrm{a}}^{0} \mathrm{f}_{\mathrm{a}}
$$

where $\Delta \mathrm{n}_{\mathrm{c}}^{0}, \Delta \mathrm{n}_{\mathrm{a}}^{0}$ and $\mathrm{f}_{\mathrm{c}}, \mathrm{f}_{\mathrm{a}}$ are the intrinsic birefringences and orientation functions of crystalline and amorphous phases respectively. 
$X$ is the fractional crystallinity. One may determine $f_{c}$ and $X$ independently using another technique such as wide angle $X$-ray and thus deduce the individual amorphous and crystalline contributions.

Polymers $A$ and $B$ are of equal density and have a similar birefringence that is also comparable with that of cold drawn LDPE of the same density. 55 Moreover, Buckley and Long ${ }^{2}$ have shown that the orientation produced by solid-state extrusion at a given draw ratio is to a reasonable approximation the same as that for a fiber drawn to the same degree. We may then make the assumption that at a given EDR, A has the same orientation as a Union Carbide LLDPE film of density 0.920 $\mathrm{g} / \mathrm{cm}^{3}$ and solid-state coextruded at room temperature using a split billet. Since no $x$-ray measurements on our samples have been yet made, we may use the x-ray data for the latter polymer. These data have been kindly provided by T. Kanamoto from the Science University of Tokyo, Japan. The orientation of the c-axis as reported in Figure 21 is used to determine the crystalline and amorphous contributions to the birefringence, $\Delta n_{c}$ and $\Delta n_{a}$ respectively, as well as the amorphous orientation as following:

$$
\Delta \mathbf{n}_{c}=X \Delta n_{c}^{0} f_{c}
$$

Combining (4) and (5), we get:

$$
\Delta \mathrm{n}_{\mathrm{a}}=\Delta \mathrm{n}_{\mathrm{T}}-\mathrm{X} \Delta \mathrm{n}_{\mathrm{c}}^{0} \mathrm{f}
$$




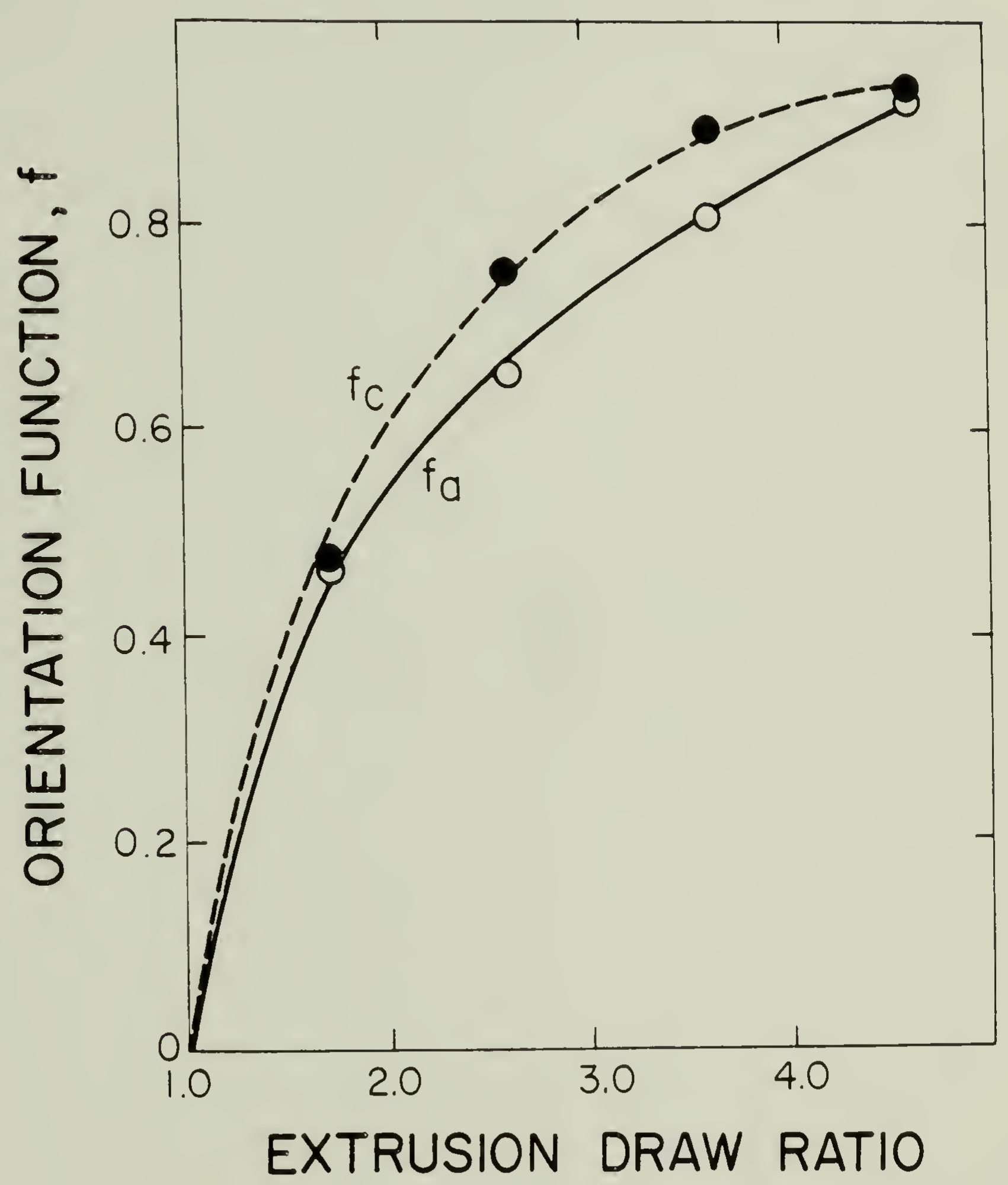

Figure 21. Crysta11ine, $f_{c}$, and amorphous, $f_{a}$, orientation functions versus EDR for sample A extruded at room temperatare. 
and

$$
\mathrm{f}_{\mathrm{a}}=\frac{\Delta \mathrm{n}_{\mathrm{a}}}{(1-\mathrm{X}) \Delta \mathrm{n}_{\mathrm{a}}^{0}}
$$

Crystallinity does not change significantly during extrusion. We use therefore $X=0.50(\mathrm{Table} 19)$ for al1 draw ratios. $\Delta \mathrm{n}_{\mathrm{c}}^{0} 54=0.057$ and $\Delta \mathrm{n}_{\mathrm{a}}^{0} 54=0.043$. The results are illustrated in Figures 21 and 22 .

Figure 22 shows that the crystalline birefringence is higher than the amorphous. Although the latter levels off earlier than the former, they both increase with draw in approximately the same way as does the total birefringence. This is consistent with observations made by Stein and co-workers ${ }^{54-56}$ for cold-drawn LDPE and by Zachariades et al.11 for solid state extruded HDPE. Figure 21 shows that amorphous orientation is comparable to the crystalline one but takes place more rapidiy: $f_{a}=$ 0.93 and $f_{c}=0.92$ at $E D R=4.6$. This is inconsistent with the observation 55 that amorphous orientation is lower than the crystalline phase in LDPE cold-drawing: $\mathrm{f}_{\mathrm{a}}=0.69$ and $\mathrm{f}_{\mathrm{c}}=0.84$.

Uncertainties in birefringence translate into imprecision in $\mathrm{f}_{a}$ of almost 20\%. Caution must thus be observed on drawing conclusions. However, if the trend shown in Figure 21 is real and the above assumption is true, it means that solid state extrusion, as opposed to cold-drawing, produces higher amorphous orientation. The reason may be related to the lateral constraints at the wall. Zachariades et al. 11 consider that the enhanced properties of the solid-state extrudate compared with the drawn material are due to the better lateral fit of the fibrillar elements and the better compaction of the structural 


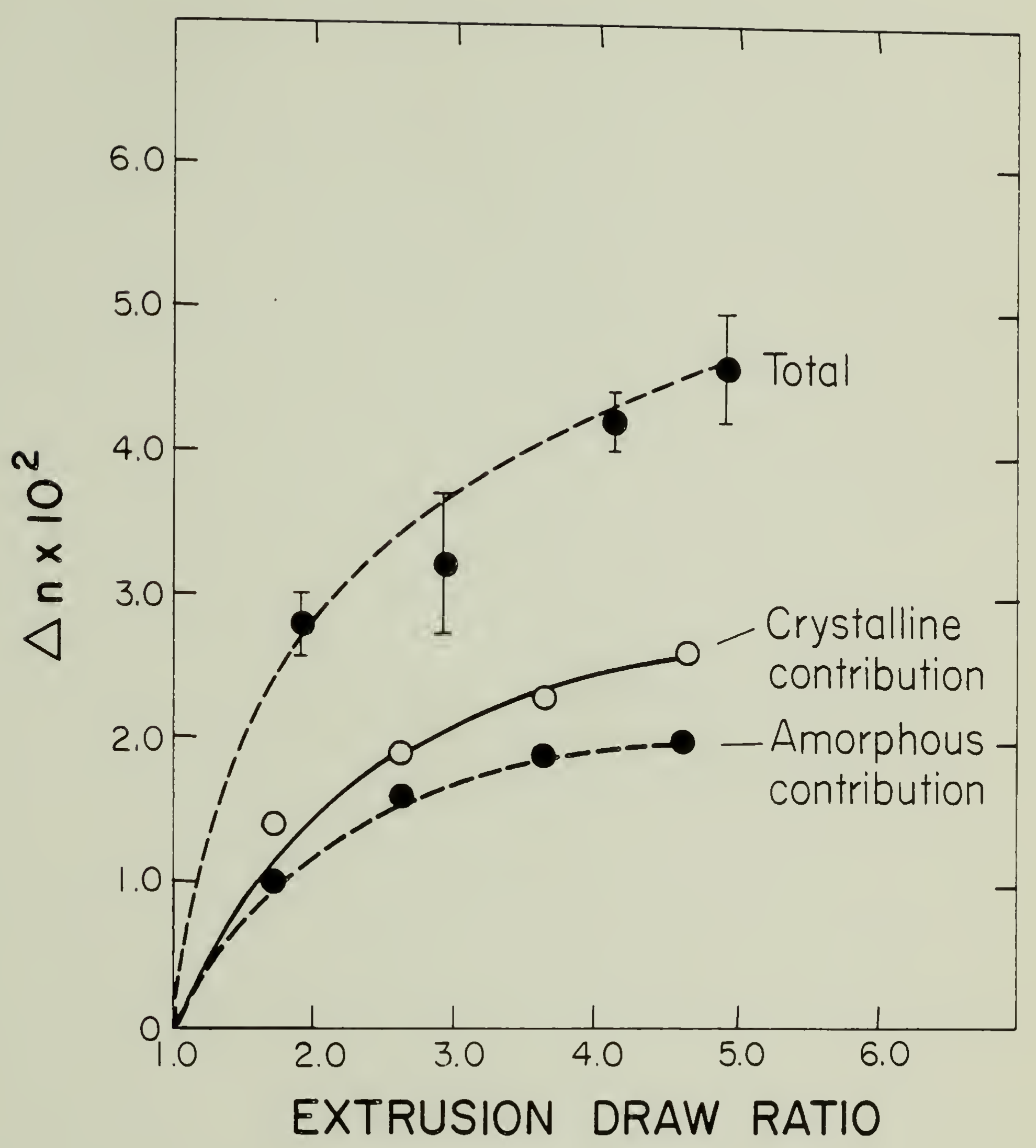

Figure 22. Crystalline and amorphous contributions to birefringence of sample A extruded at room temperature. 
defects at the microfibrils ends due to compressive stresses. LDPE orients more rapidiy, though not as much, than HDPE extruded in same conditions: $\quad f_{c}=0.0864$ at $E D R=6.2$ and $T_{e x}=80^{\circ} \mathrm{C} .11$ This is consistent with observations made for cold drawing 56 and also with the more rapid increase in modulus for the former (Chapter IV, Section 3 ). The reason, according to Stein 56 is that intercrystalline "interference" reduces the ability of the crystals to orient.

\subsection{Thermal conductivity}

Orientation in extruded polymers can also be evaluated by measuring the thermal conductivity along the draw direction. This is because oriented polymers have an enhanced conductivity for heat along the chain direction. For highly oriented polyethylene, conduction has been found to approach that of copper in the draw direction. 26 Thermal conductivity measurements for extruded polymers $A, B$, C are presently being carried out in our laboratory by $J$. Jonza and $J$. Parmer using the flash method. In this technique, 57,58 the radiant energy of a flash lamp is used to pulse heat at the front surface of a suspended cylindrical sample. The transient temperature difference $\theta(t)$ between the front and back surface, as sensed by attached thermocouples, is recorded as a function of time:

$$
\theta(t)=\theta_{0} \sum_{m=1,3, \ldots} \exp \left(-m^{2} t / t_{c}\right)
$$


where $\theta_{0}$ is an instrumental constant and $t_{c}$ a constant characteristic of the sample. For $t>0.6 t_{c}, \theta(t)$ behaves as a simple exponential decay curve from which the thermal diffusivity a can be extracted:

$$
a=L^{2} / \pi^{2} t_{c}
$$

where $L$ is the sample length in cylindrical geometry. Finally, thermal conductivity $K$ is deduced from the relation:

$$
\mathbf{K}=\rho \mathbf{C} \boldsymbol{a}
$$

where $\rho$ and $C$ are the density and the specific heat respectively. The former has been measured (Chapter IV, Section 1.2) and the 1atter can be obtained from 1 iterature.

The first results, kindly provided by $J$. Jonza, are reported in Figure 23 which shows a definite increase of thermal conductivity along the draw direction $\mathrm{K} / \mid$ with EDR for polymers $A$ and B extruded at $60^{\circ} \mathrm{C}$. Using the least square method, it is found that the increase is 1 inear and similar, i.e. straight lines are parallel, for both polymers. Ontil more measurements are carried out and on other samples, it will not be possible to assess whether or not the linearity is general. Nevertheless, the increase is real and large with the values comparable to those of Choy et a1. 57 for LDPE films drawn at room temperature. It is interesting to note that thermal conductivity, birefringence and tensile modulus all increase with draw and provide therefore a 


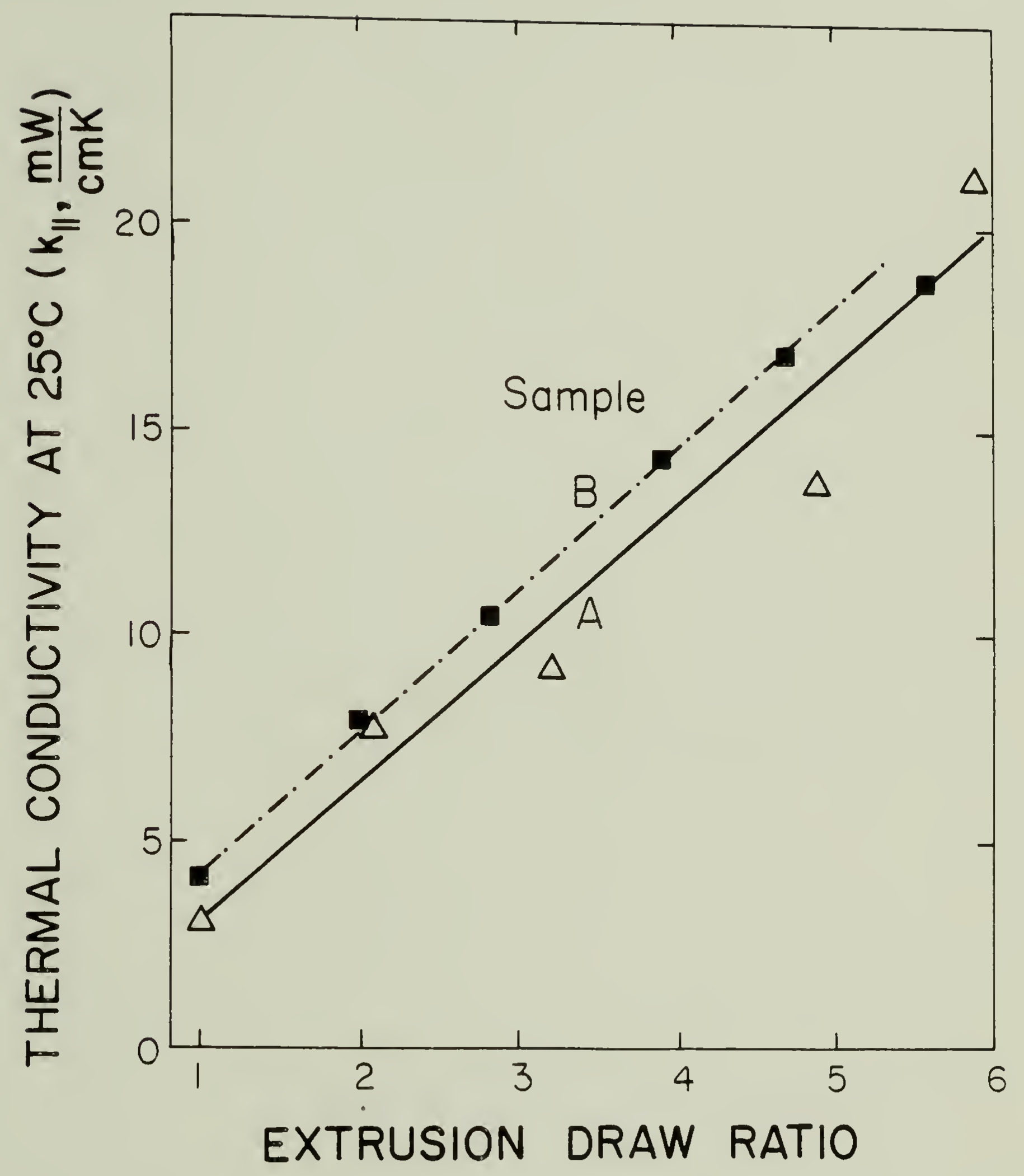

Figure 23. Axial thermal conductivity versus EDR for samples A $(\Delta)$ and $B(D)$ extruded at $60^{\circ} \mathrm{C}$. 
qualitative way of evaluating overall orientation. Yet, each of these properties change by a different pattern. 


\section{H A P T E $R$}

\section{CONCLUSION}

Unlike in solid-state extrusion of HDPE, high draw ratios have not readily been achieved in a single stage solid-state extrusion of low density polyethylene, i.e. EDR $\sim 7$ is the highest obtained. The linear LDPE draws more easily than the branched one but both strain harden. Substantial orientation, despite some loss through die swe11, takes place during LDPE extrusion as evidenced by an increase in transparency, modulus, birefringence, and thermal conductivity along the draw direction. No major changes in crystallinity are observed for the three polymers as assessed by density and DSC measurements. Two unusual features are observed: a decrease in melting point with draw ratio for polymer $B$ and a minimum in modulus at low draw ratios for all three polymers. Morphological changes, i.e. lamellar to microfibrillar structure, are thought to take place during extrusion as evidenced by strain hardening but need to be confirmed by structural studies such as x-ray which will be undertaken as part of our future work.

Future plans also include drawing the same polymers in a multi-stage coextrusion which will hopefully enable us to achieve draw ratios beyond the present limits. The extrusion process and the sample preparation used in this study can be readily applied in industry. Thus, despite the limitation in draw, the properties enhancement, i.e. modulus, transparency and thermal conductivity, are significant enough for possible industrial applications. 


\section{List of References}

1. H. U1rich, "Introduction to Industrial Polymers", Hanser, New York (1981).

2. A. Buckley and H.A. Long, Polym. Eng. Sci., 9, 115 (1969).

3. J.M. Alezander and P.J.H. Worme11, Annals. C.I.R.P., XVIV, 21 (1971).

4. N. Capiati, S. Kojima, W. Perkins, and R.S. Porter, J. Mater. Sci., 12. $334(1977)$.

5. W.T. Mead and R.S. Porter, J. Polym. Sci., Polym. Symp., 63, 289 (1978).

6. S. Kojima and R.S. Porter, J. App1. Polym. Sci., App1. Polym. Symp., 33. $129(1978)$.

7. W.G. Perkins, N.J. Capiati, and R.S. Porter, Polym. Eng. Sci., 16, $200(1976)$

8. H.H. Chuah, R.E. DeMiche1i, and R.S. Porter, accepted for publication, J. Polym. Sci., Polym. Lett. (1982).

9. J.H. Southern, R.S. Porter, and H.E. Bair, J.Polym. Sci., A-2, 10, 1135 (1972).

10. S. Kojima, C.R. Desper, and R.S. Porter, J.Polym. Sci., Polym. Phys. Ed., 16, 1721 (1978).

11. A.E. Zachariades, W.T. Mead, and R.S. Porter, "U1tra-High Modulus Polymers", A. Ciferri and I.M. Ward (Editors), Applied Science, Essex, England (1979).

12. N.E. Weeks and R.S. Porter, J. Polym. Sci., Polym. Phys. Ed., 13, $2049(1975)$ 
13. J.H. Southern and R.S. Porter, J. Macromo1. Sci.-Phys., B4, 541 (1970).

14. W.T. Mead and R.S. Porter, Intern. J. Polym. Mater., I, 29 (1979).

15. J.H. Southern and R.S. Porter, J. App1. Polym. Sci., 14, 2305 (1970).

16. D.J.H. Sandiford and A.H. Willbourn, "Polythene", A. Renfrew and P. Morgan (Editors), Iliffe and Sons, London (1960).

17. G.L. Wilkes, J. Macromo1. Sci.-Chem., C10, 149 (1974).

18. G. Cappaccio, A.G. Gibson and I.M. Ward, "Ultra High Modulus Polymers", A. Ciferri and I.M. Ward (Editors), Applied Science, Essex, England (1979).

19. M. Takayanagi, "Deformation and Fracture of High Polymers", H.H. Kausch, J.A. Hasse11, R.I. Jaffee (Editors), Plenum Press, (1972). 20. G.R. Sne11ing and J.F. Lontz, J. App1. Polym. Sci., $\underline{3}, 257$ (1960).

21. F. DeCandia, A. Peru110, V. Vittoria, and A. Peterlin, J. Appl. Polym. Sci., 28, 1815 (1983).

22. P.S. Hope and B. Parsons, Polym. Eng. Sci., 20, 597 (1980).

23. F. DeCandia, R. Russo, and V. Vittoria, and A. Peterlin, J. Polym. Sci., Polym. Phys. Ed., 20, 269 (1982).

24. P.S. Hope and B. Parsons, Polym. Eng. Sci., 20, 589 (1980). 25. J.A. Brydson, "Flow Properties of Polymer Melts", p. 78, George Godwin, London (1981).

26. R.S. Porter, "Exploring the Limits of Polymer Properties: Preparation Methods and Evaluation", NSF proposal.

27. F. DeCandia, R. Russo, V. Vittoria, and A. Peterlin, J. Polym. Sci., Polym. Phys. Ed., 20, 1175 (1982). 
28. R.S. Porter, personal communication.

29. A. Tsuruta, T. Kanamoto, K. Tanoka, and R.S. Porter, unpublished.

30. R.S. Porter, Amer. Chem. Soc., Polym. Prep., 12, 36 (1971).

31. A. Peterlin, "Ultra High Modulus Polymers", A. Ciferri and I.M. Ward (Editors), Applied Science, Essex, England (1979).

32. Z. Tadmor and C.G. Gogos, "Principles of Polymer Processing", P. 264, Wiley, New York (1979).

33. J. Shultz, "Polymer Materials Science", p. 210, Prentice-Ha11, New Jersey (1974).

34. J. Prandrup and E.H. Immergut, "Polymer Handbook", p. VI 44, Interscience Publishers, New York (1967).

35. W. Glenz, N. Morosoff, and A. Peterlin, J. Polym. Sci. Polym. Lett., 9. $211(1971)$.

36. F. DeCandia, R. Russo, V. Vittoria, and A. Peterlin, J. Polym. Sci. Polym. Phys. Ed., 20, 269 (1982).

37. P. Meares, "Polymers: Structure and Bulk Properties", Chapter 5, Van Nostrand Reinhold, London (1965).

38. B. Wunderlich, "Macromolecular Physics", $\underline{3}$, Academic Press, New York (1980)

39. S.M. Aharoni and J.P. Sibilia, J. App1. Polym. Sci., 23, 133 (1979).

40. P.S. Hope, A.G. Gibson, and I.M. Ward, J. Polym. Sci. Polym. Phys. Ed. , 18, $1243(1980)$.

41. J. Clements, G. Capaccio, and I.M. Ward, J. Polym. Sci. Polym. Phys. Ed.. I, 693 (1979).

42. W.T. Mead and R.S. Porter, J. App1. Phys., 47, 4278 (1976). 
43. J.P. Be 11 and J.H. Dumbleton, J. Polym. Sci., A-2, I, 1033 (1969). 44. G.E. Sweet and J.P. Be11, J. Po1ym. Sci., A-2, 10, 1273 (1972). 45. D.P. Pope, J. Polym. Sci. Polym. Phys. Ed., 14, 811 (1976).

46. L. Koski, J. Therma 1 Ana 1., 13, 467 (1978).

47. I.M. Ward, "Mechanical Properties of Solid Polymers", Chapter 10, Wiley, London (1971).

48. V.B. Gupta, A. Ke11er, and I.M. Ward, J. Macromo1. Sci. Phys., B2 $139(1968)$.

49. D.W. Hadley, P.R. Pinnock, and I.M. Ward, J. Mater. Sci., 4, 152 (1969).

50. F.C. Frank, V.B. Gupta, and I.M. Ward, Phi1. Mag., 21, 1127 (1970).

51. V.B. Gupta and I.M. Ward, J. Macromo1. Sci. Phys., B2, 89 (1968).

52. V.B. Gupta and I.M. Ward, J. Macromo1. Sci. Phys, B1, 373 (1967).

53. I.M. Ward, J. Polym. Sci. Polym. Symp., 58, 1 (1977).

54. S. Hoshino, J. Powers, D.G. Legrand, H. Kawai, and R.S. Stein, J. Polym. Sci., 58, 185 (1962).

55. R.S. Stein and F.H. Norris, J.Polym. Sci., 21, 381 (1956).

56. R.S. Stein, J. Po1ym. Sci., 34, 709 (1959).

57. C.L. Choy, F.C. Chen, and W.H. Luk, J. Polym. Sci. Polym. Phys., 18, 1187 (1980).

58. F.C. Chen, Y.M. Poon, and C.L. Choy, Polym., 18, 129 (1977). 


\section{APPENDIX}

\section{Relaxation Modulus}

The relaxation modulus measurements are made by carrying out a ramploaded stress relaxation test where the ramp rates are low. Using linear viscoelasticity, the stress for such a strain input is given by:

$$
\sigma(t)=\int_{0}^{t} E_{r}(t-\xi) \frac{\partial \varepsilon}{\partial \xi} d \xi
$$

where $\sigma(t)$ is the stress output at time $t, E_{r}$ the relaxation modulus, $\varepsilon$ the strain input, and

$$
\frac{\partial \varepsilon}{\partial \xi}=\left\{\begin{array}{l}
\varepsilon=\varepsilon_{0} / t_{0} \quad \text { when } \xi \leq t_{0} \\
0 \quad \text { when } \xi>t_{0}
\end{array}\right.
$$

For $t>t_{0}$

$$
\sigma(t)=\varepsilon \int_{0}^{t} 0 E_{r}(t-\xi) d \xi
$$

After a change of variables $a=t-\xi$, we obtain:

$$
\bar{E}(t)=\frac{\sigma(t)}{\varepsilon_{0}}=\frac{1}{t_{0}} \int_{t-t_{0}}^{t} E_{r}(\alpha) d \alpha
$$

$\bar{E}(t)$ in (3) is the average relaxation modulus between time $t-t_{0}$ and $t$ (Figure 24). At long times $t \gg t_{0}$, this average is the relaxation modulus. Experimentally, and at sufficiently long times $\left(t \geq 10 t_{0}\right)$, the relaxation modulus is equal to the ratio $\sigma(t) / \varepsilon_{0}$. Equation (3) can be used only if our materials are linear viscoelastic. 

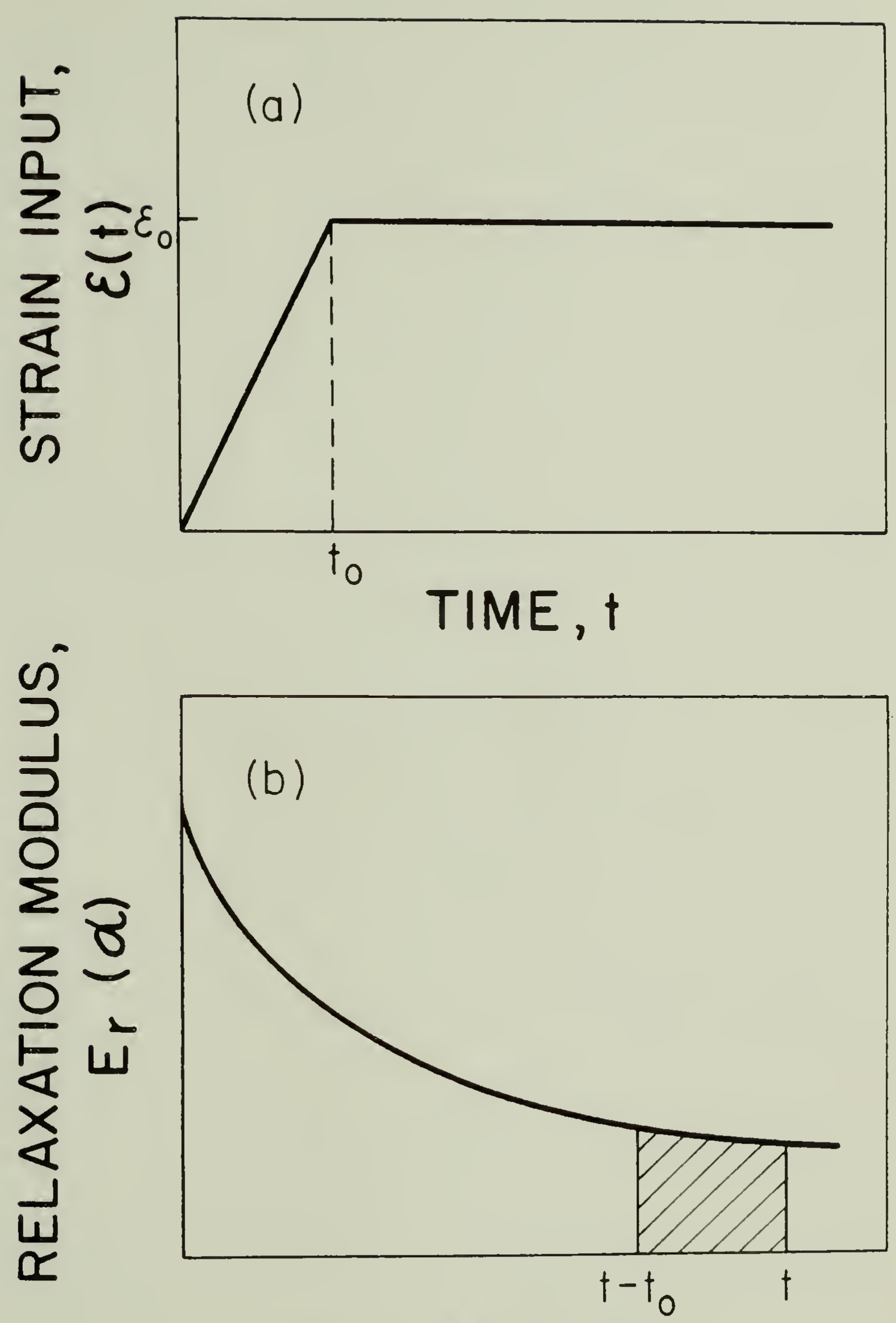

TIME, $\propto$

Figure 24. Strain input (a) and relaxation modulus (b) in a ramp-loaded stress relaxation. 
The requirements of 1 inearity are met when:

(i) multiplying the strain input by a scalar C results in multiplying the stress output by $C$.

(ii) Boltzmann superposition is applicable.

Since researchers may consider a material linearly viscoelastic if it satisfies condition ( $i$ ), we limited ourselves to checking this condition.

One extrudate, $\mathrm{DR}=3.0$ and $\mathrm{T}_{\mathrm{ex}}=22^{\circ} \mathrm{C}$, was tested to verify whether polymer $A$ is linearly viscoelastic. First, we strain the material at different strain rates and compare the ratios of the output (stress) and input (strain) obtained after 1.0 minute at each strain. Table 28 shows that our sample is linearly viscoelastic within an uncertainty of $12 \%$, for strains $\varepsilon \leq 1 \%$.

Table 28

Stress Output to Strain Input Ratio
Strain Rate (cm/min)
$\sigma / \varepsilon(\operatorname{Re} 1$ ative Units)
$\langle\sigma / \varepsilon\rangle$

$\begin{array}{lll}0.02 & 1.9 \pm 0.1 & \\ 0.05 & 1.72 \pm 0.03 & 1.72 \pm 0.2 \\ 0.10 & 1.54 \pm 0.03 & \end{array}$

Second, we strain the sample in the same manner but we let it relax. Then we calculate the relaxation modulas $E_{I}(t)=\frac{\sigma(t)}{\varepsilon_{0}}$ at different relaxation times $t$. The results are summarized in Table 29. The average relaxation modulus at $t$ ime $t=10$ min is $E_{r}(10)=120 \pm 20$ 
$\mathrm{MPa}$. The uncertainty is then of $\sim 17 \%$. Since $E_{r}(t)$ is practically equal to $E_{r}(10)$. within this uncertainty, we have chosen to measure $E_{r}(5)$ instead of $E_{r}(10)$ for practical convenience. Similarly, polymers $B$ and $C$ are shown to be linearly viscoelastic within an uncertainty of less than $15 \%$. The uncertainty over their relaxation moduli is less than $20 \%$.

Table 29

Relaxation Modulus of Polymer A Extruded at $80^{\circ} \mathrm{C}$ and DR $=3.0$ For Different Strain Rates and Relaxation Times

\begin{tabular}{lccc}
\hline$t_{0}(\mathrm{~min})$ & $\varepsilon(\mathrm{cm} / \mathrm{min})$ & $E_{\mathrm{r}} \begin{array}{c}(5 \mathrm{~min}) \\
(\mathrm{MPa})\end{array}$ & $\begin{array}{c}E_{\mathrm{r}}(10 \mathrm{~min}) \\
(\mathrm{MPa})\end{array}$ \\
\hline 0.5 & 0.02 & -106 & 145 \\
0.5 & 0.05 & 151 & 121 \\
1.0 & 0.10 & 127 & 113 \\
\hline
\end{tabular}

Reference: R.J. Farris, M.S. Thesis, University of Utah (1969). 



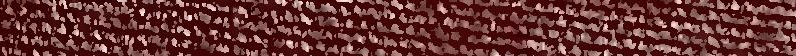

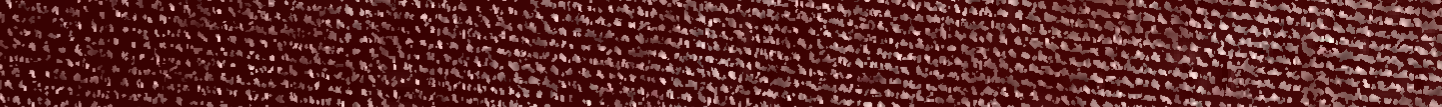

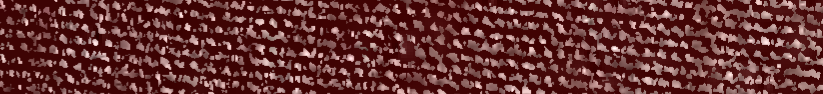

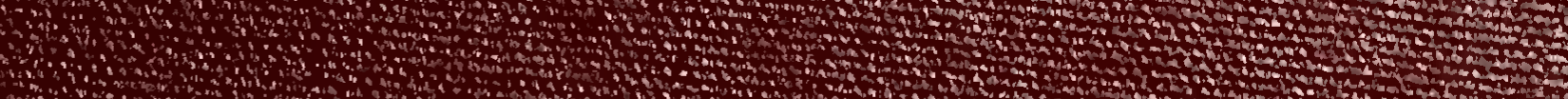

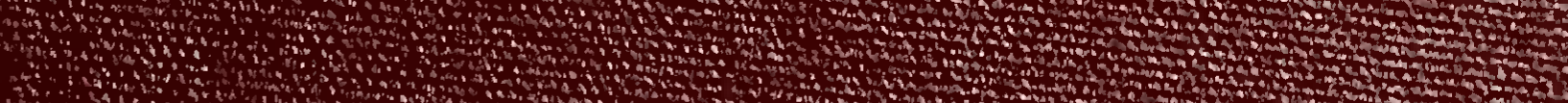

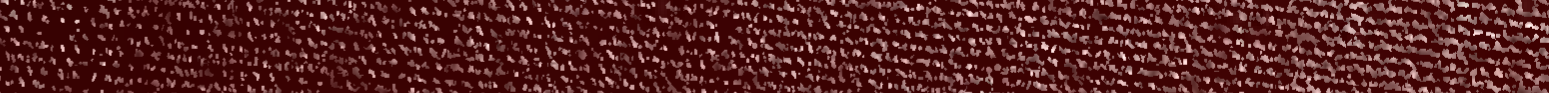
Hot

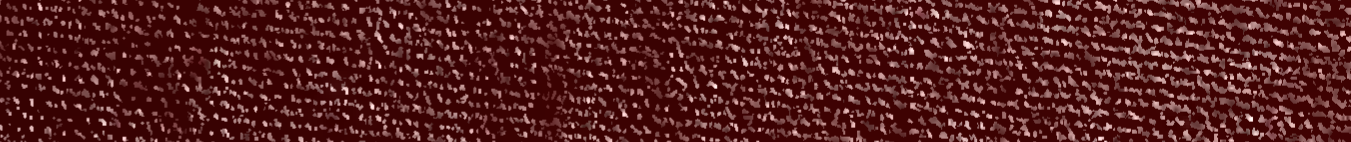

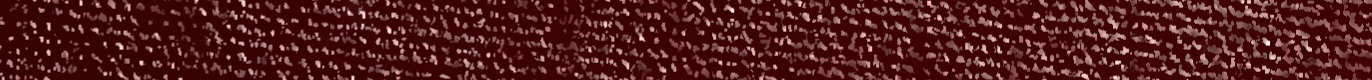

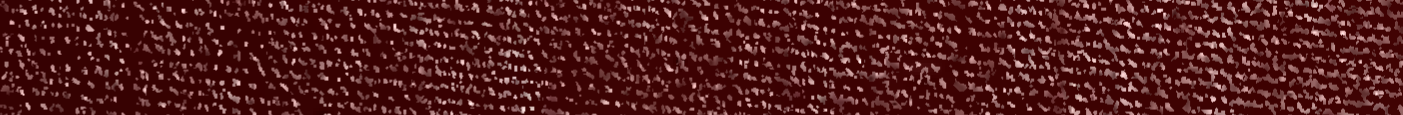
-

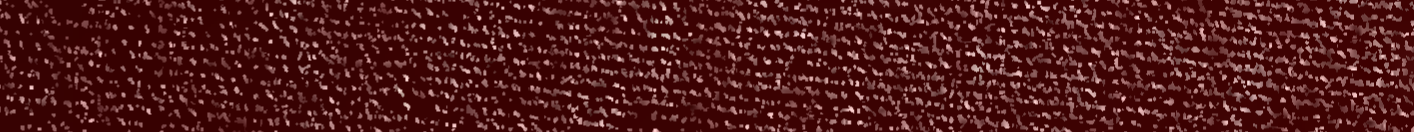

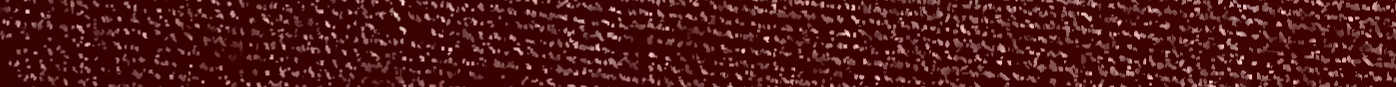

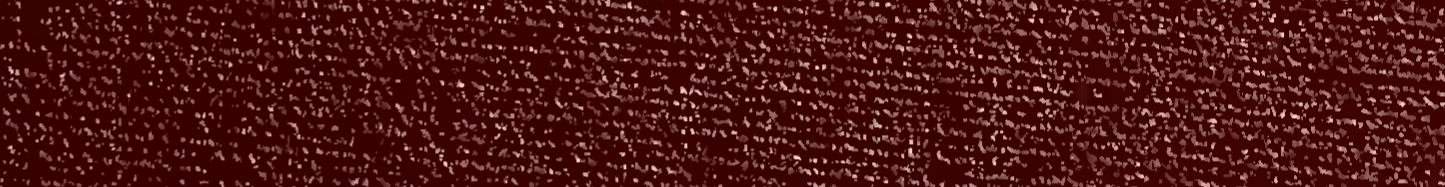
(n)

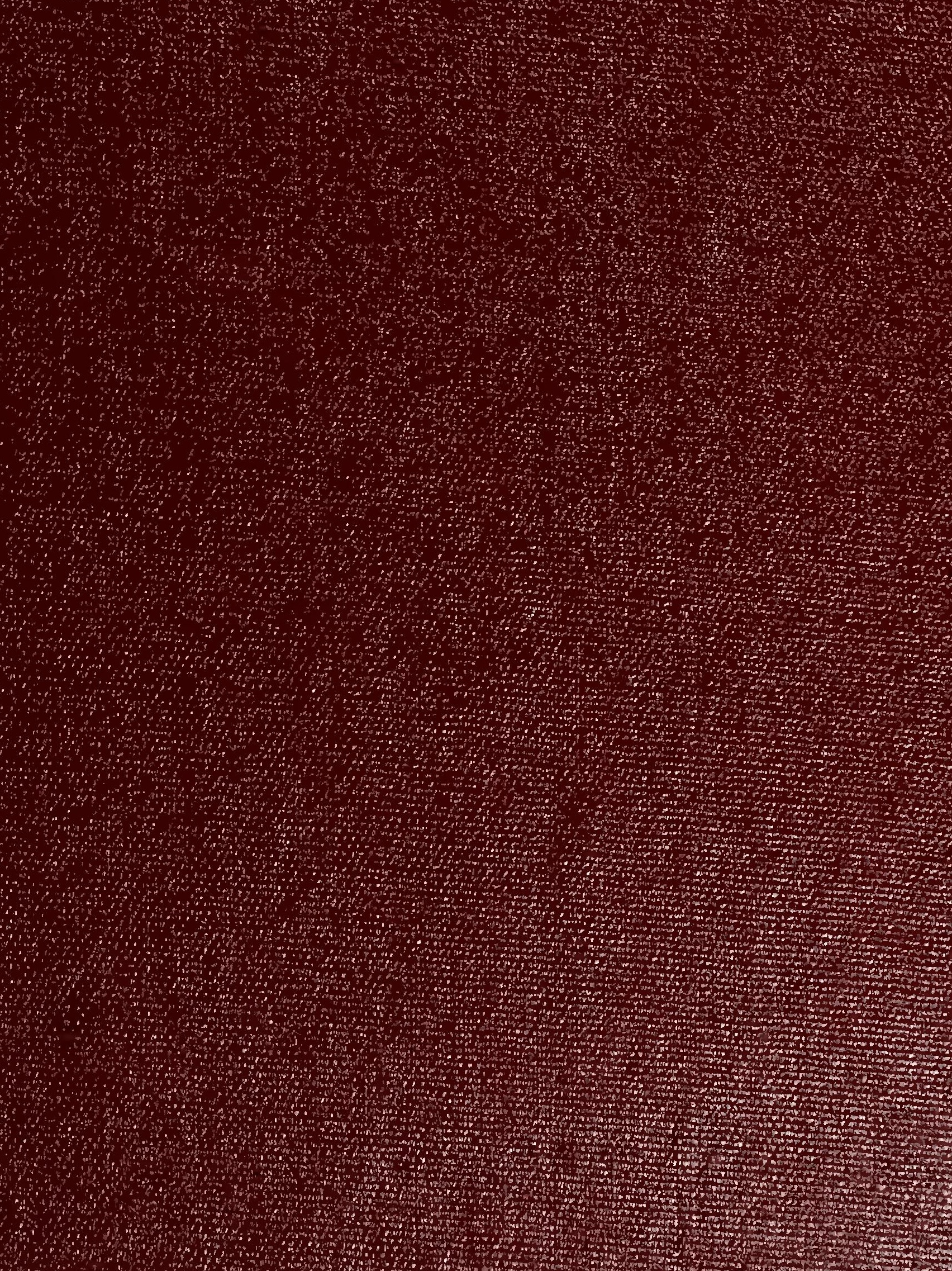

